د. - مبد شاطر عبد الرحمن

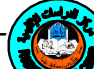

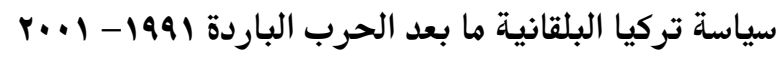

\author{
عبد شاطر عبد الرحمن \\ مدرس مساعد/ كلية العلوم السياسية/ جامعة الموصل
}

ملخص البحث

يحتل إقليم البلقان مكانة مهمة في الإدراك الإستراتيجي التركي، لاعتبارات الجوار الجغرافي والارتباطات

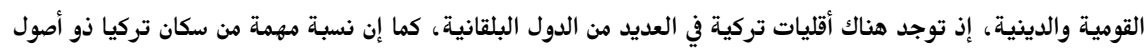
بلقانية، فضلا عن ما يبديه المسلمون في البلقان من علاقة ترابطية تجاه تركيا. مثلت نهاية الحرب الباردة وتفكك الاتحاد السوفيتي السابق وانهيار المعسكر الشيوعي بمثابة إزالة الحاجز

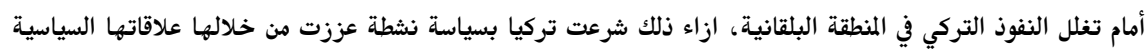
والعسكرية والاقتصادية مع العديد من الدول البلقانية.

المقدمة وفرت نهاية الحرب الباردة وانهيار المنظومة الاشتراكية في شرق أوربا والبلقان وتفكك الاتحاد السوفيتي السابق وتلاشي تأثيره في هذه المناطق فرصة جديدة لتركيا لسد فراغ القوة Power Vacuum الأمر، لكن مع تفكك يوغسلافيا في مطلع التسعينيات من القرن العشرين وظهور حالة عدم الاستقرار في الأقليم البلقاني أخذت بوادر القلق بالازدياد لدى أنقرة على الرغم من عدم وجود تهديد مباشر للأمن التركي نتيجة ما يحصل هناك. لكن القلق التركي كان ينبع من وجود اعداد كبيرة من مواطني تركيا ذات أصول بلقانية تربطهم علاقات قرابة مع إقرانهم في البلقان، فضلا عن وجود أقليات تركية في العديد من الدول البلقانية. إزاء ذلك شرعت تركيا في سياسة نشطة في منطقة البلقان سواء في الميدان الدبلوماسي أو المساهمة في العمليات العسكرية ضمن إطار هيئة الأمم المتحدة والمنظمات الدولية أو من خلال بناء علاقات ثنائية سياسية وعسكرية واقتصادية مع بعض بلدان المنطقة، وانعكس ذلك على العلاقات التركية- اليونانية بأن أصبحت المنطقة البلقانية ميدانا لتنافس 
تتكون هيكلية البحث من مقدمة وثلاثة مباحث فضلا عن الخاتمة. تناول المبحث الأول التأصيل التاريخي لأبعاد السياسة التركية في البلقان، في حين عالج المبحث الثاني علاقات تركيا مع الدول البلقانية الشيوعية السابقة وتطور هذه العلاقات في اطار من المعاهدات الثنائية السياسية والاقتصادية والعسكرية. أما المبحث الثالث فقد كرس لدراسة العلاقات التركية- اليونانية وتطور النزاع بين البلدين حول قضية قبرص وبحر ايجة ومن ثم التنافس التركي- اليوناني في مذطقة البلقان.

المبحث الأول : التأصيل التاريخي لأبعاد السياسة التركية تجاه البلقان حتى نهاية الحرب الباردة

البلقان هو الاسم الذي يطلق على شبه الجزيرة التي تقع في جنوب شرق أوربا ويحدها من

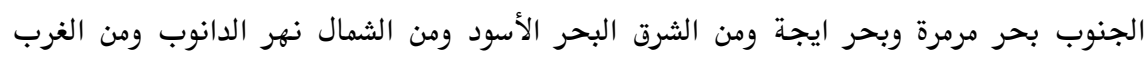

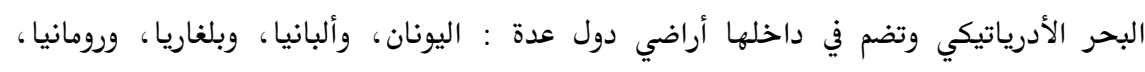

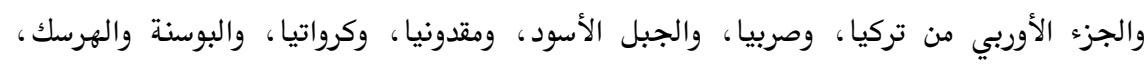

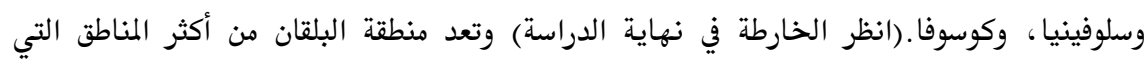

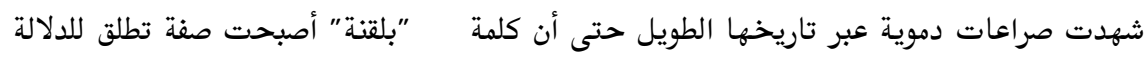
على الصراعات والنزاعات الداخلية ذات الطبيعة الدموية والتفكيكية (1). إن أبعاد السياسة التركية تجاه البلقان متعددة ومتنوعة تشكلت في إطار من العلاقات التاريخية

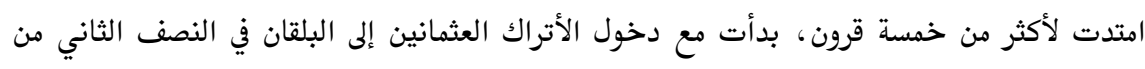
القرن الرابع عشر الميلادي، إذ احكم العثمانيون خلال تلك الفترة سيطرتهم على معظم دول البلقان

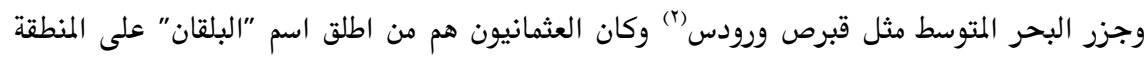
وتعني الجبل المغطى بالغابات الكثيفة ، كما وعرفت المنطقة أيضا بأسم "تركيا الأوربية"(()).

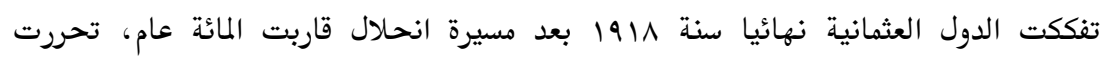
خلالها معظم الدول التي كانت تحت سيطرتها ومن ضمنها الدول البلقانية، حيث حصلت اليونان

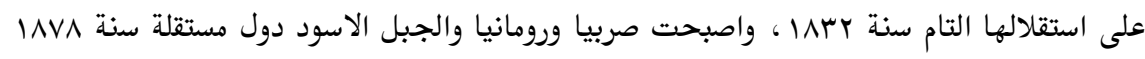


وتم وضع البوسنة والهرسك تحت ادارة امبراطورية النمسا-المجر التي قامت بضمها بشكل نهائي

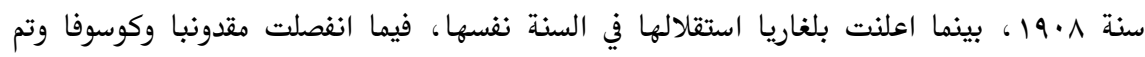

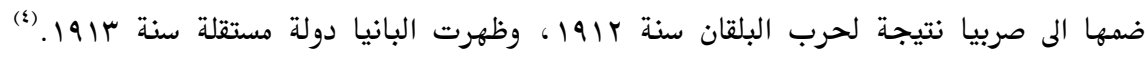

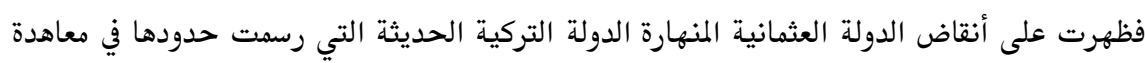

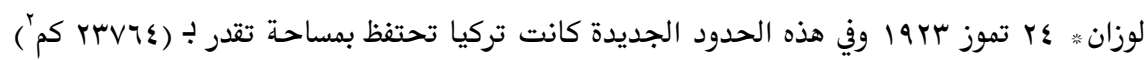
في شبه الجزيرة البلقانية.() وهي اكبر من مساحة بعض الدول البلقانية (سلوفينيا أو الجبل الأسود).

وتم خلال القرون الثلاثة الأولى من السيطرة العثمانية على البلقان خلق وجود أسلامي في العديد

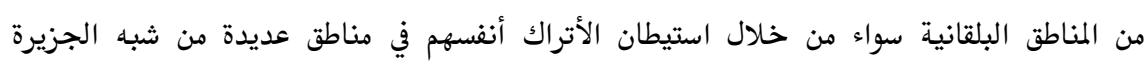

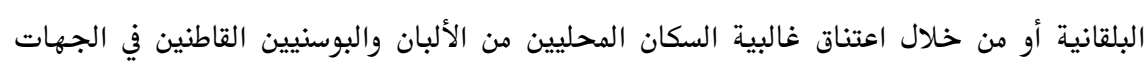

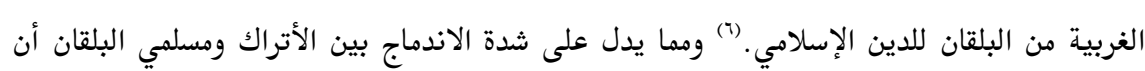

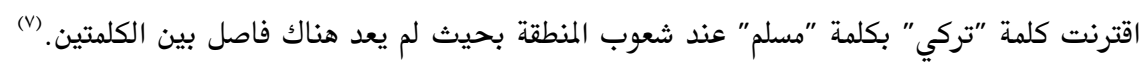

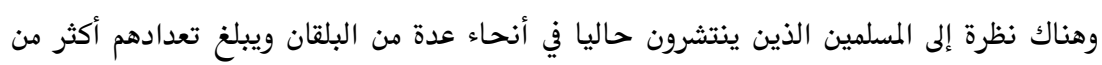
تسعة ملايين على إنهم جزء من الإرث العثماني التركي، وإنهم امتداد وذراع لتركيا في المنطقة ،

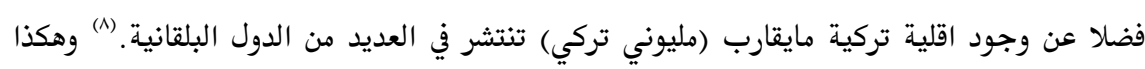

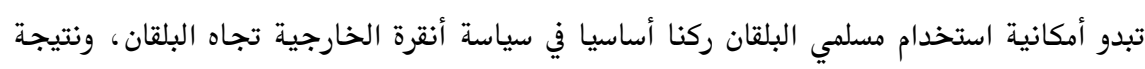

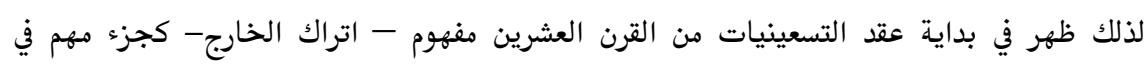

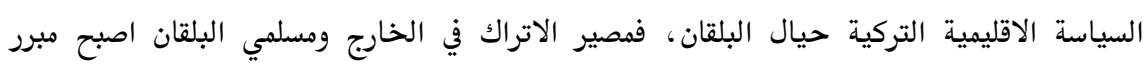

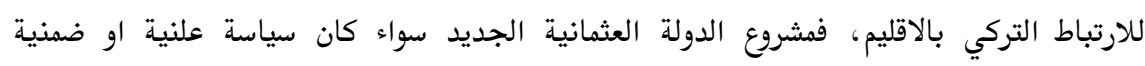

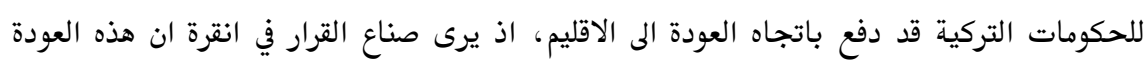

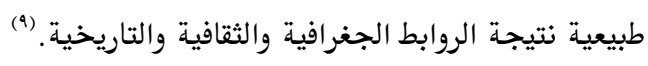

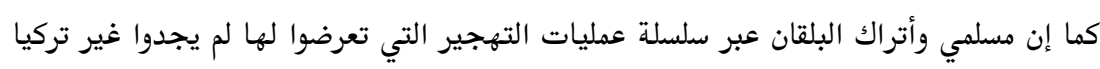

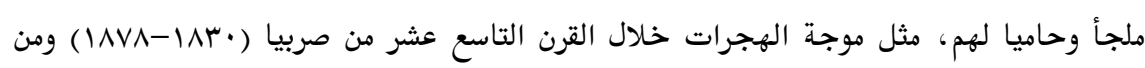

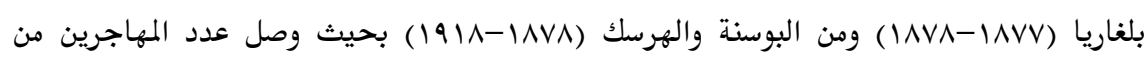

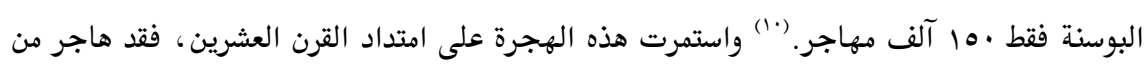




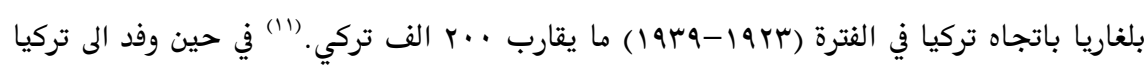

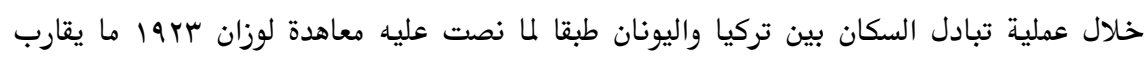
•

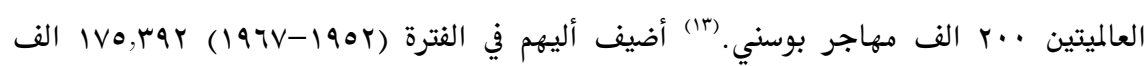

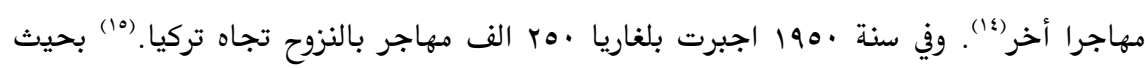

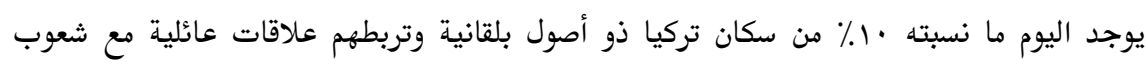
المنطقة البلقانية. (17)

كانت تركيا دائمة الحضور في الترتيبات السياسة والأمنية البلقانية، فمنذ تأسيسها سنة بra 19

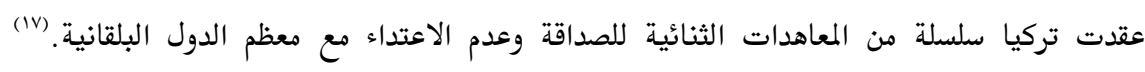

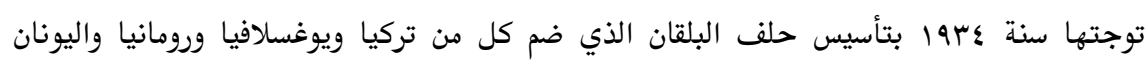
بقصد الوقوف بوجه المطالب البلغارية التعديلية لواقع رسم الحدود في البلقان الذي أوجدته

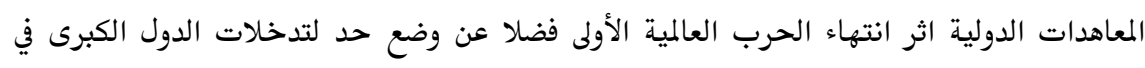

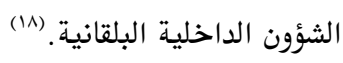
وخلال مؤتمر مونترو Montreux حول المضايق التركية (البوسفور والدردنيل) الذي عقد الدئل

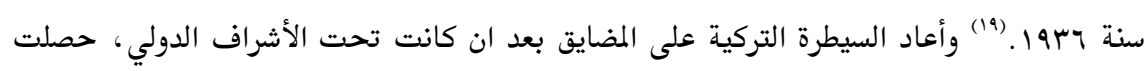

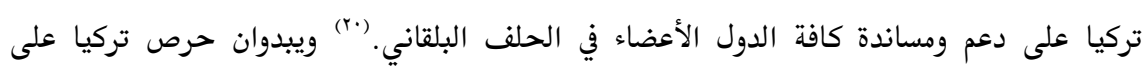
توطيد علاقاتها مع الدول البلقانية هو بغية تكرار ذلك الدعم في الحصول على التأيد البلقاني للمساعي التركية الرامية إلى الانضمام إلى الاتحاد الأوربي.

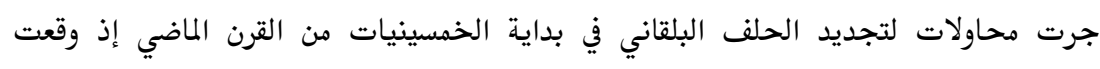

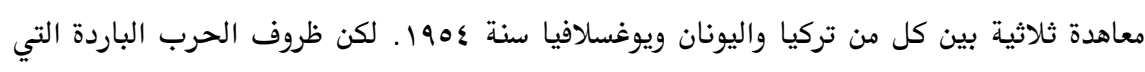

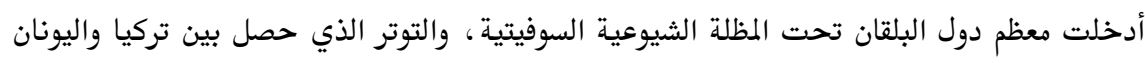

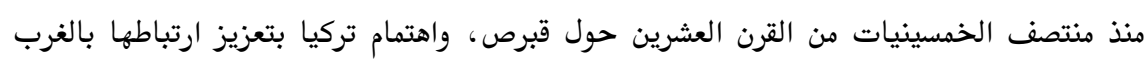

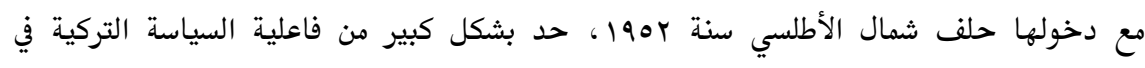
البلقان أبان حقبة الحرب الباردة. (ri) 
يعد اقليم البلقان اقليم جذب للقوى الاقليمية والدولية ومنها تركيا لما يتمتع به من خصائص ومميزات، فقد برز اقليم البلقان تاريخيا كأحد المناطق الحيوية والاستراتيجية التي شغلت مساحة واسعة في التفكير السياسي والامني الاوربي خاصة في القرن التاسع عشر ضمن اطار "المسألة الشرقية" التي كانت تعني في حقيقتها تنازع القوى الاستعمارية الاوربية لأنتزاع مذطقة البلقان من السيطرة العثمانية. وفي الوقت الحاضر فان الموقع الجغرافي الحيوي الذي يتمتع به اقليم البلقان بسبب توسطه، تقريبا، القارة الاوربية ومتاخمته لمنطقة البحر المتوسط المهمة للخطوط الملاحية الدولية، وقربه الى حد ما من منابع النفط في الشرق الاوسط، جعله محل تنافس القوى الدولية والأقليمية. (rr) وفي ضوء المكانة التي احتلها اقليم البلقان في الادراك الأستراتيجي التركي عد الاقليم لاعتبارات الجوار الجغرافي والارتباطات القومية والدينية مجالا للنفوذ التركي بعد الحرب الباردة. أذ يشكل الحضور الجغرافي التركي في البلقان حضورا إستراتيجيا، فتركيا بوابة البلقان إلى أسيا كما أن البلقان بوابة تركيا إلى أوربا الغربية كونه معبرا لمليونان ونصف المليون من الأتراك العاملين في أوربا الغربية وممرا لأكثر من نصف التجارة الخارجية التركية مع تلك المنطقة. (rr) أضف الى ذلك ان مذطقة البلقان تقع على مفترق طرق أستراتيجية أوربية ثلاث، طريق الدانوب، والطريق نحو الشمال، وطريق الجنوب عبر الجبال البلقانية، ثم ان نهر الدانوب يمثل طريق المستقبل اذا ما تم انشاء قناة تربطه بنهر الراين تسمح مرور بواخر من وزن ·. … طن تكون وجهتها بحر الشمال والبلطيق والبحر الابيض المتوسط وبحر الأسود حيث تقع منابع النفط في الشرق الأوسط وبحر قزوين، وتعد

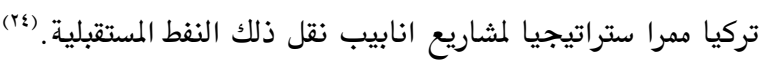
وهناك اهمية اضافية للبلقان بالذسبة لتركيا تأتي من موقعه المتاخم للاتحاد الاوربي المعني بضم دول البلقان الى الاتحاد الاوربي، ليس فقط لاحتواء الازمات البلقانية وانما للاستفادة من موارده البشرية والزراعية لتفعيل الاقتصاد الأوربي.(†) وبالتالي فان حرص انقرة على التواجد الفعال والاندماج في منطقة البلقان ياتي في سياق طموحها للأنضمام الى الاتحاد الاوربي. وبناء على ما تقدم يبدو انه من الاهمية بمكان ان يحتل الاستقرار في البلقان، الذي شهد اضطرابا كبيرا مع مطلع التسعينيات، مرتبة عالية على سلم أولويات السياسة الخارجية التركية خشية العواقب الوخيمة المحتملة لأي اضطراب بلقاني على صعيد "الانتقال بالعدوى". لذا حرصت 
تركيا على توجيه سياستها البلقانية نحو استقرار الأنظمة الجديدة إما عبر تطوير علاقات ثنائية موسعة مع العديد من الدول البلقانية، فضلا عن دعم الجهود متعددة الأطراف الرامية إلى تحسين

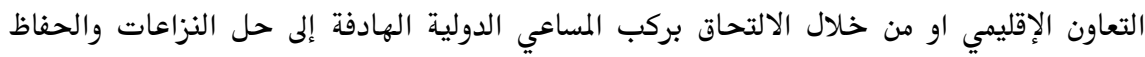
على السلم في المنطقة. (ri)

\section{المبحث الثاني: تركيا والدول البلقانية الشيوعية السابقة}

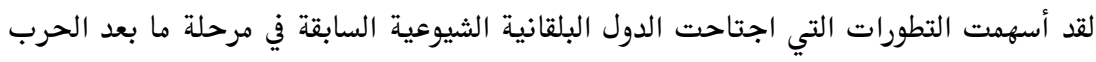

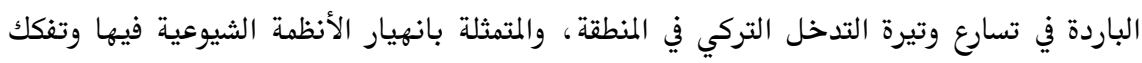

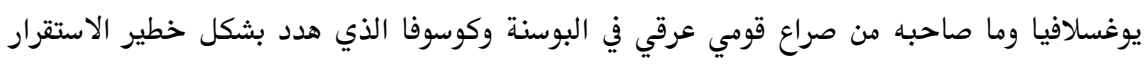
الإقليمي البلقاني وزاد من امكانية اتساع الصراع ليشمل المنطقة البلقانية برمتها ومن ضمنها لونها تركيا.

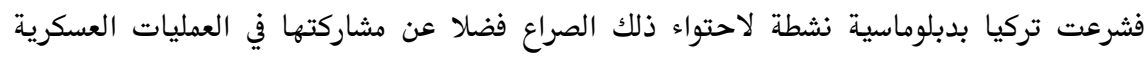

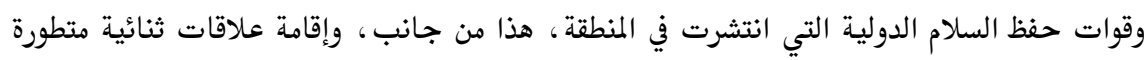
مع كل من بلغاريا، ورمانيا، ومقدونيا، وألبانيا من جانب أخر.

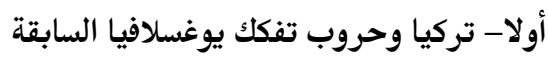

كانت يوغسلافيا السابقة، من وجهة نظر صربية، تمثل في جوهرها مشروع قومي صربي، كان

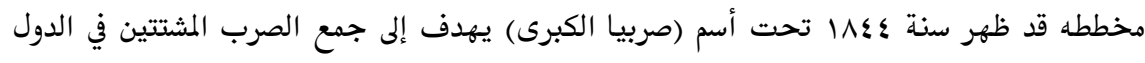

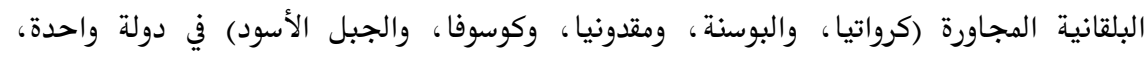
وعندما أصبح ذلك المشروع القومي حقيقة واقعة سنة 1911 بقيام الدولة اليوغسلافية كان إصرار

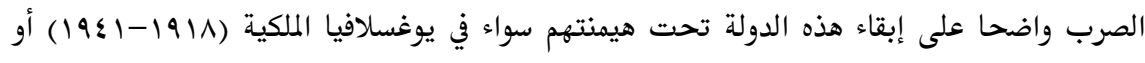
يوغسلافيا الاتحادية الاشتراكية (9£0-1994) وذلك بفرض المركزية في إدارة البلاد وهيمنة الصرب على كل مؤسسات الدولة الإدارية والعسكرية والأمنية. (vV)

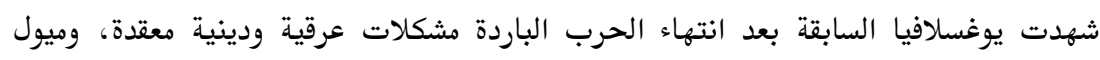
قومية خاصة من قبل الصرب ذوي النزعة القومية المتطرفة الرامية الى اعادة اقامة دولة "صربيا 
الكبرى" على حساب تطهير القوميات الاخرى وبخاصة المسلمين الالبان في كوسوفا والمسلمين

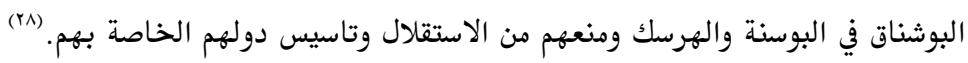

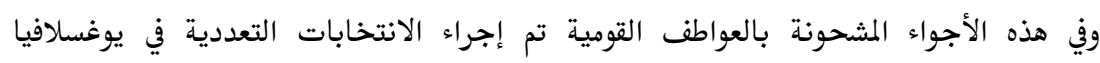
السابقة سنة .199 وكان الفوز فيها لصالح الأحزاب القومية في جميع الجمهوريات اليوغسلافية

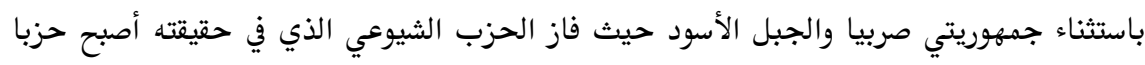

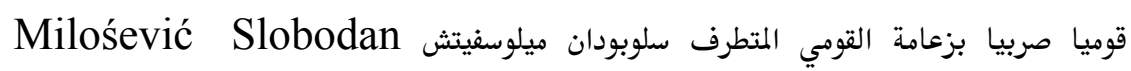

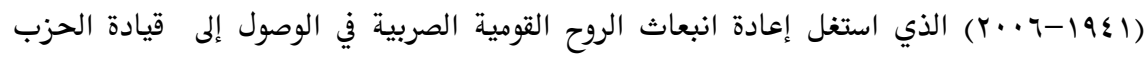

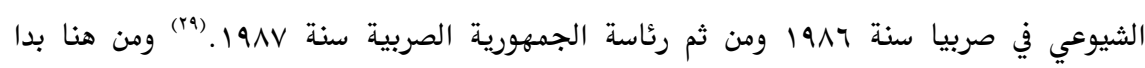
الصدام بين الطرفين عندما طالبت الأحزاب القومية باستبدال الرابطة الفدرالية برابطة كونفدرالية أي تخفيف حدة المركزية أو البديل هو الانفصال عن الاتحاد، وتبنت سلوفينيا وكرواتيا الخيار

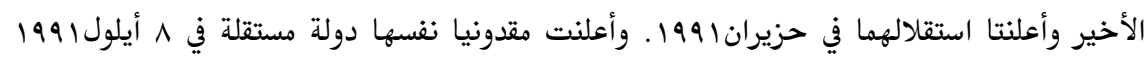

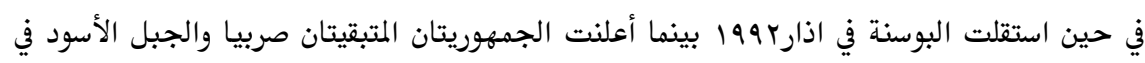
1 M نيسانrا99 اتحادهما تحت اسم (جمهورية يوغسلافيا الاتحادية) واعتبرتا نغسيهما الوريثنين

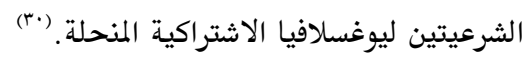
رفضت صربيا استقلال هذه الجمهوريات ودخلت في صراع عسكري مسلح مع سلوفينيا في

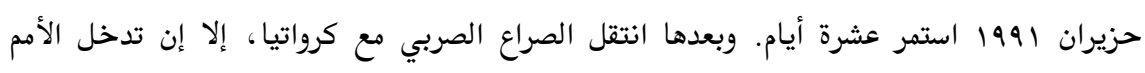

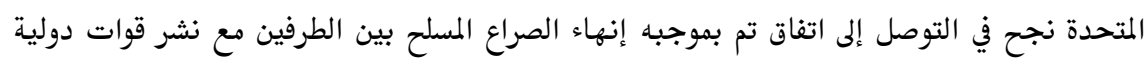
لاحفظ السلام. (بإ) أما في البوسنة فقد شنت مليشيات من صرب البوسنة وبدعم من الجيش الحكومي الصربي

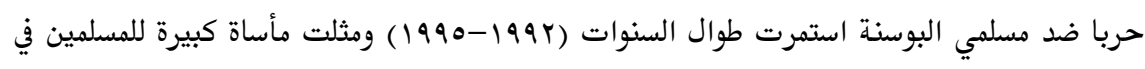

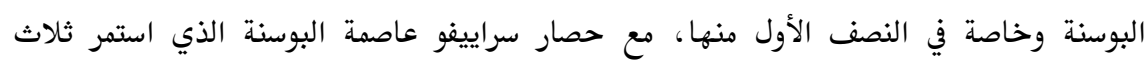

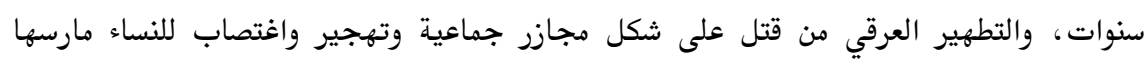

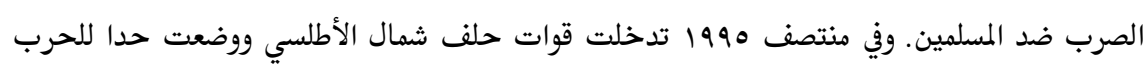

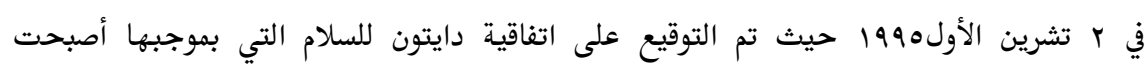

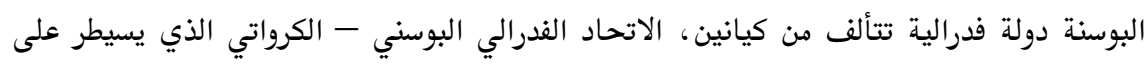


دراسات إقليمية 7 (17) مركز الدراسات الإقليمية

10٪ من أراضي البلاد، وجمهورية الصرب (صربسكا) التي تسيطر على 9؛٪٪ الباقية، مع حكومة وطنية واحدة تتمتع برئاسة ثلاثية بالمداورة. (rآ) رفضت أنقرة في البداية تقسيم جمهورية يوغسالافيا الاتحادية الاشتراكية السابقة خشية ان يكون تقسيم يوغسلافيا نموذج يعمم على جميع دول البلقان الأمر الذي يشكل خطرا على سلامة الأراضي التركية التي تهددها المطالب الانفصالية لأكراد تركيا.(rr) لكن مع اعتراف الاتحاد الاوربي بجميع الدول المنفصلة عن الفدرالية اليوغسلافية اعترفت تركيا ايضا بتلك الدول مطلع سنة ب99 1. (؟r) وقد تركزت سياسة تركيا تجاه بلدان يوغسلافيا السابقة على دعم مصالح المسلمين في البوسنة والهرسك

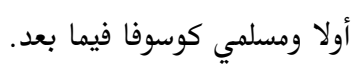
1- تركيا ومسلمو البوسنة: بدأت تركيا خلال حرب البوسنة (1994-1990) التي شهدت

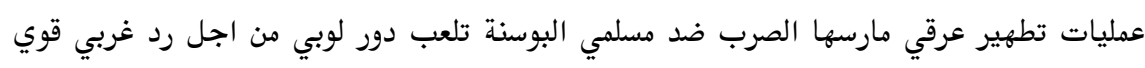

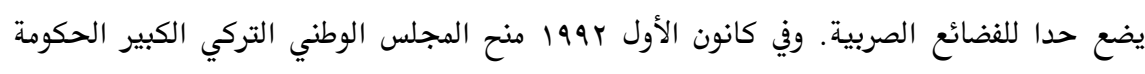

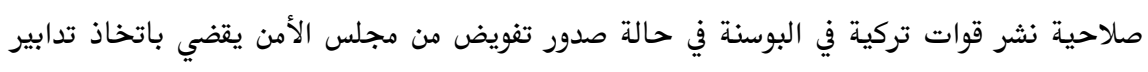

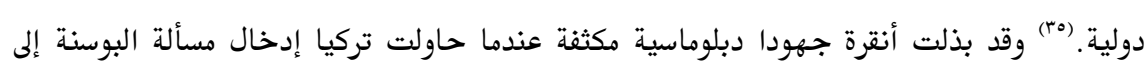

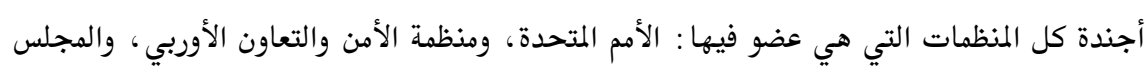

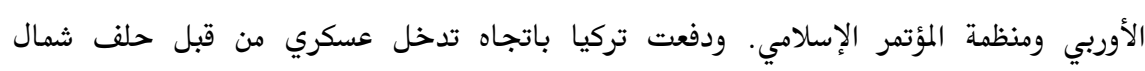

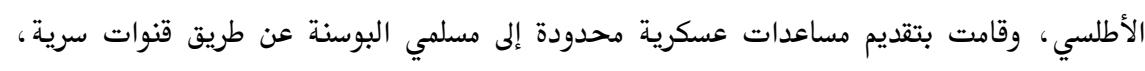
ورحبت بالجهود الأمريكية لإنهاء العنف في البوسنة الذي أرسته معاهدة السلام في دايتون (") 1990

وقام وزير الخارجية التركي حكمت હَيتن Hikmet Çetin خلال حرب البوسنة بزيارات عدة إلى العاصمة البوسنية سراييفو، وكثف من جهوده الدبلوماسية في عدد من الدول بقصد الحيتّن الحصول

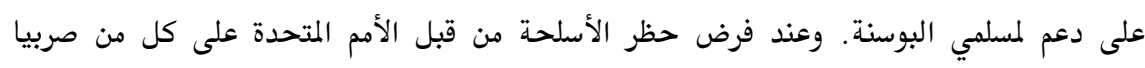

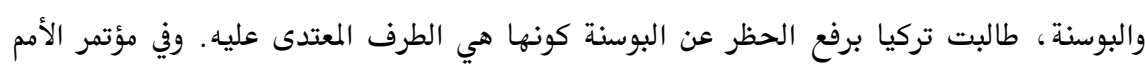

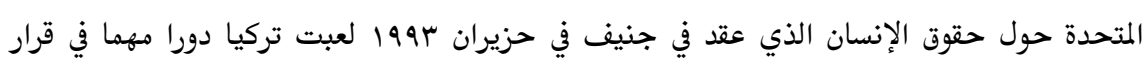

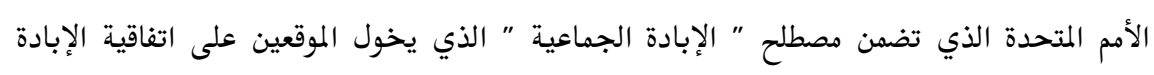


الجماعية الحق في التدخل في البوسنة بشكل فردي أو جماعي، وقبل هذا القرار بالإجماع. وكانت تركيا أول بلد يفتتح سفارة له في البوسنة. (rv)

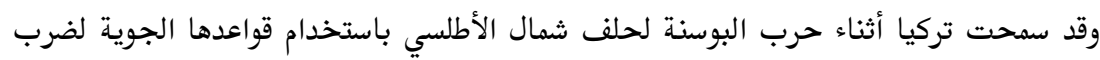

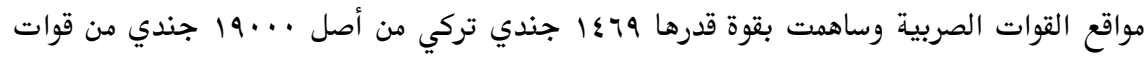

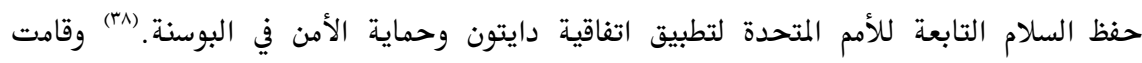
بتدريب مجاميع من الجيش البوسني. ومنحت تركيا قرضا إلى البوسنة والهرسك بقيمة •N مليون

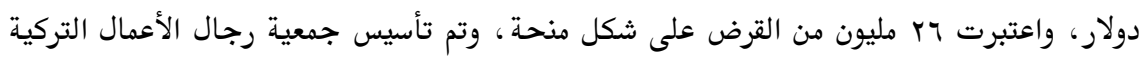

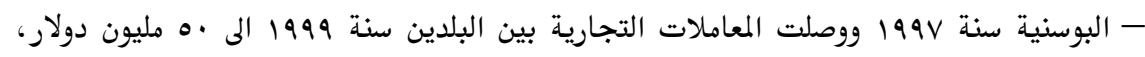
مع وجود ^؛ شركة تركية تعمل في البوسنة. (ra)

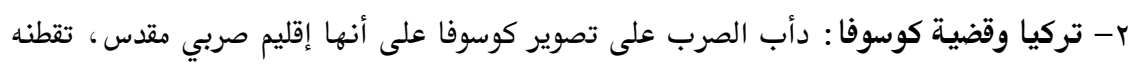
أقلية ألبانية وافدة من دولة مجاورة هي ألبانيا، جلبتها قوة أجنبية هي الدولة العثمانية إبان

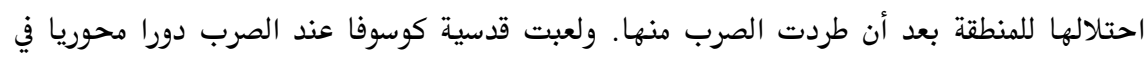

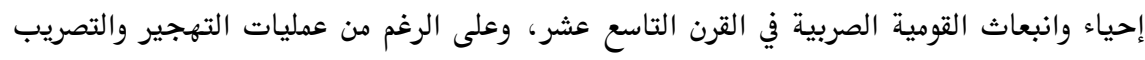

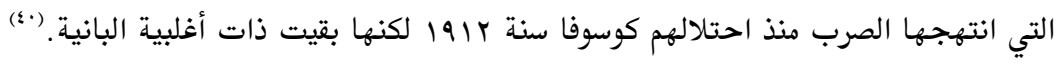

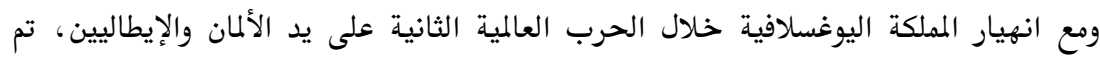

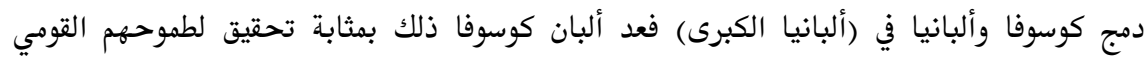

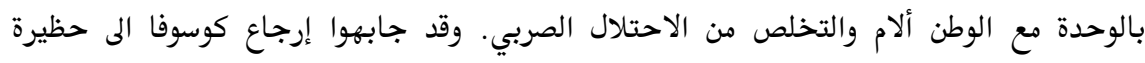

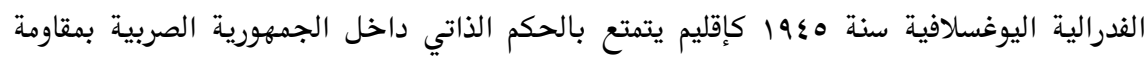

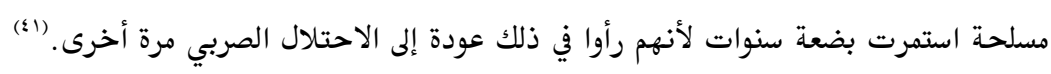
شكل الحكم الذاتي مرحلة جديدة من الاضطهاد والتهميش مارسته الأقلية الصربية في كوسوفا

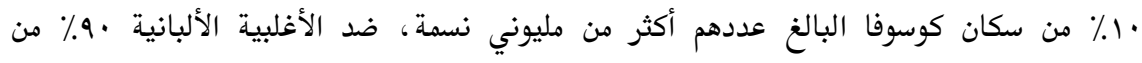

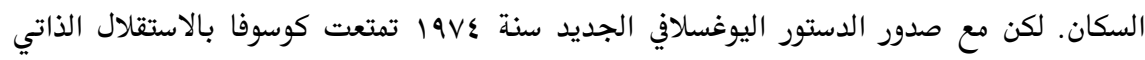

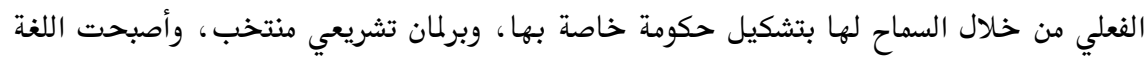

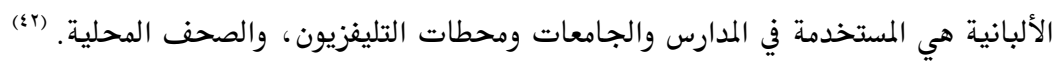


رفضت صربيا الامتيازات التي منحت إلى إقليم كوسوفا و رأت فيها انتقاص من سيادتها، فقام الرئيس اليوغسلافي السابق سلوبودان ميلوسفيتش بإلغاء الحكم الذاتي والسيطرة على الإقليم بالقوة العسكرية عام 1919، وبعد انتهاء الحرب الباردة عام 1991 أجرى سكان الإقليم استفتاء انتخبوا

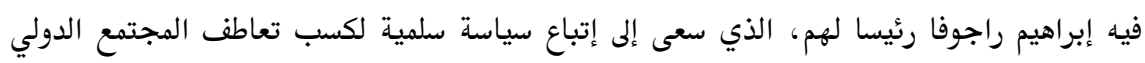
ونيل اعترافه بهذه الجمهورية الكوسوفية، واستمر هذا الحال حتى سنة 1991 ، عندما قام الرئيس سلوبودان برفض هذا الاستقلال والقيام بعمليات تطهير عرقية واسعة وعمليات تهجير ضد السكان

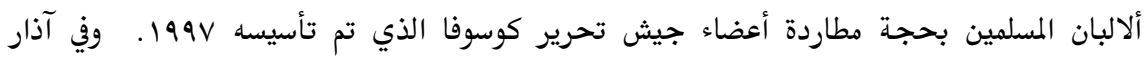

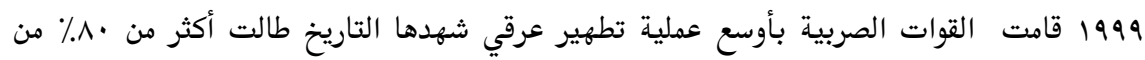

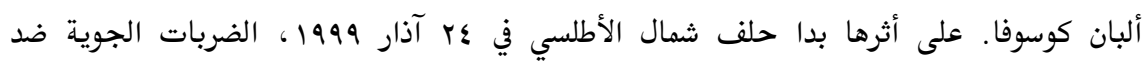

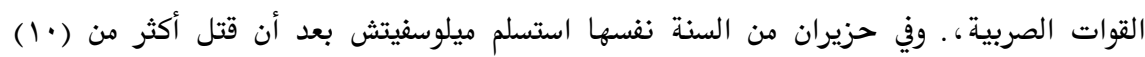

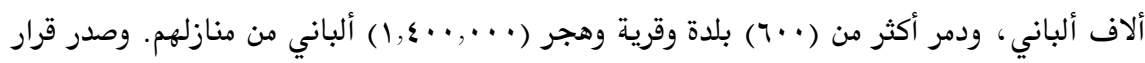

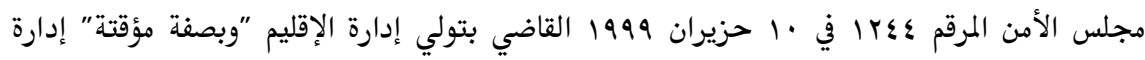

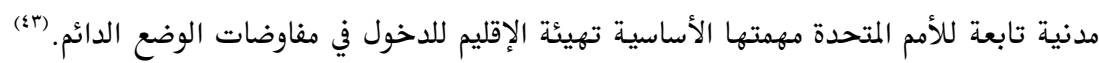
خلافا لحالة مسلمي البوسنة لم تبذل تركيا جهودا دبلوماسية فعالة بالنيابة عن ألبان كوسوفا ولم

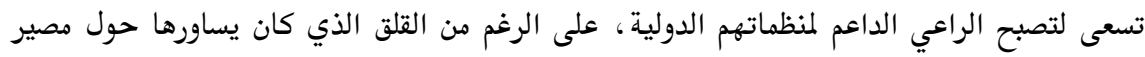

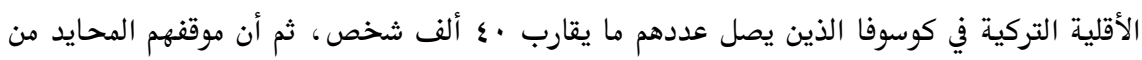

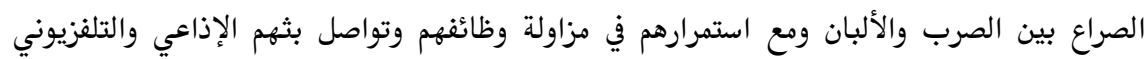
باللغة التركية، في حين حرم ألبان كوسوفا من جميع هذه الحقوق ، جعلهم في محل ريبة واتهام في

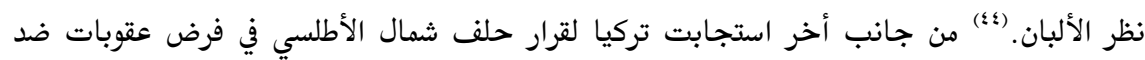

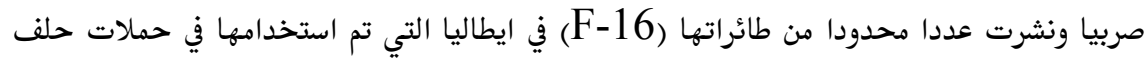
شمال الأطلسي الجوية التي شنها ضد الصرب. وساهمت على اثر نهاية الصراع في كوسوفا بـ

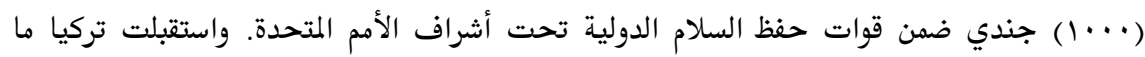
يقارب بr الف لاجئ من أهالي كوسوفا، كما ان الجرحى من جيش تحرير كوسوفا كانوا يتلقون

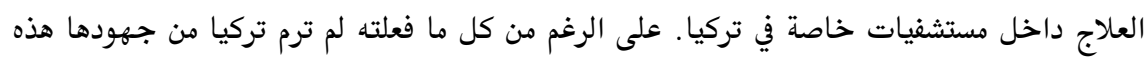


دعم كوسوفا البانية هستقلة وإنما العودة إلى حالة الحكم الذاتي لكوسوفا كما في السابق، لأنها تعاني

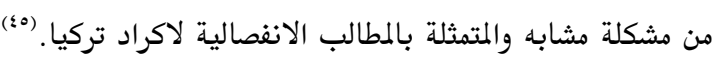
ثانيا- تركيا وبلغاريا: تحسنت العلاقات التركية مع بلغاريا في مرحلة ما بعد الحرب الباردة،

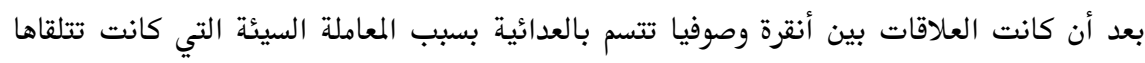

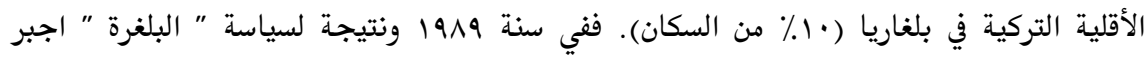

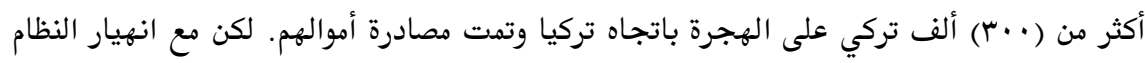

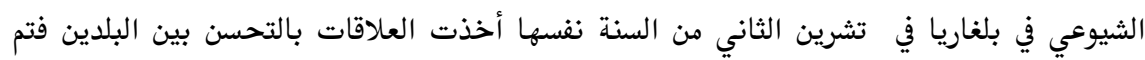

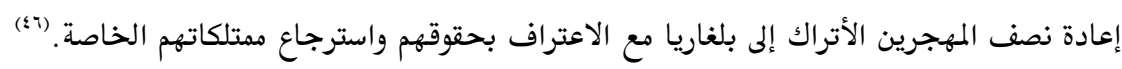
تغيرت علاقات تركيا مع بلغاريا في الجوانب العسكرية ايضا، من خلال توقيع اتفاقيات

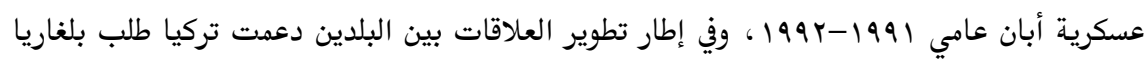

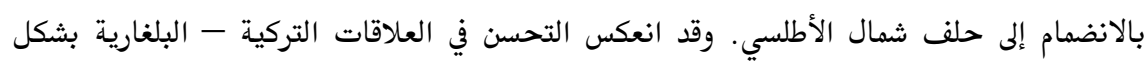

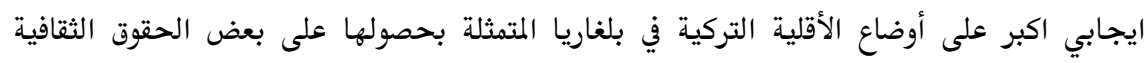
والسياسية، حيث انتظم الأتراك في حزب سياسي تحت اسم "حركة الحقوق والحرية" واخذوا يشاركون في الحياة السياسية البلغارية عندما شاركوا في الانتخابات البلغارية في تشرئ تشرين

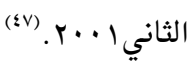
ثالثا- تركيا ورومانيا: حسنت رومانيا علاقاتها مع تركيا بعد انهيار الذظام الشيوعي فيها ووقعت اتفاقية صداقة بين البلدين سنة ال199 على اثر الزيارة التي قام بها الرئيس التركي توركت

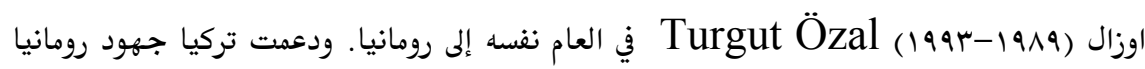
في سعيها لكسب عضوية حلف الناتو وتأتي تركيا بالمرتبة العاشرة في تسلسل الاستثمارات الخارجية

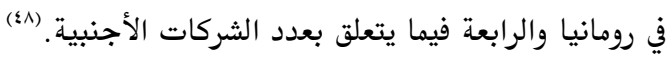
رابعا- تركيا ومقدونيا: كانت تركيا البلد الثاني بعد بلغاريا الذي اعترف باستقلال مقدونيا عن بندين

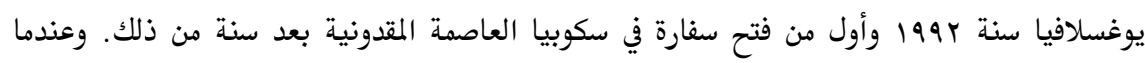
حاولت اليونان منع الاعتراف بمقدونيا وفرضت عليها حصارا وأغلقت ميناء تيسالونيكا Thessalonica 
تركيا علاقات اقتصادية وعسكرية مع مقدونيا وكسرت عزلتها، ووقعت اتفاقية للتعاون العسكري

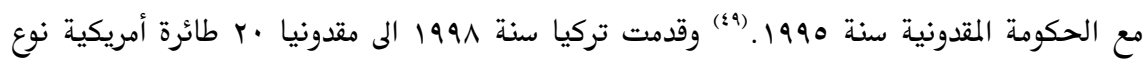
F-5S

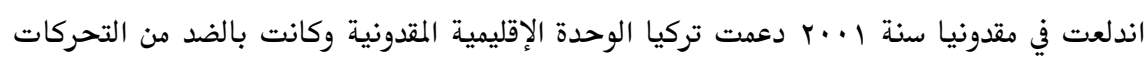

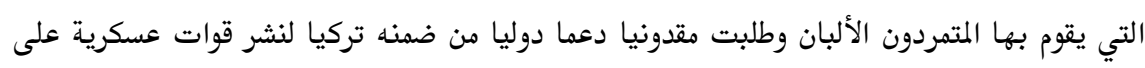
طول الحدود المقدونية - الكوسوفية. (1) خامسا- تركيا وألبانيا: تم تعزيز العلاقات التركية_ الألبانية بتوقيع اتفاقية للصداقة والتعاون

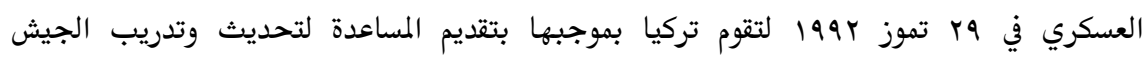

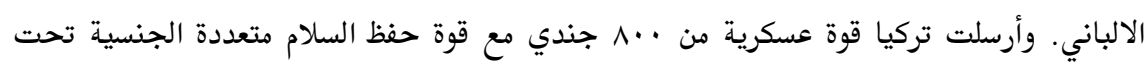

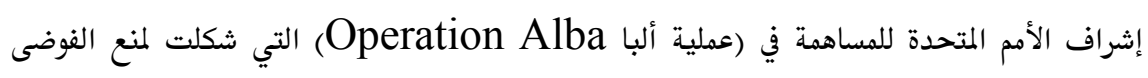

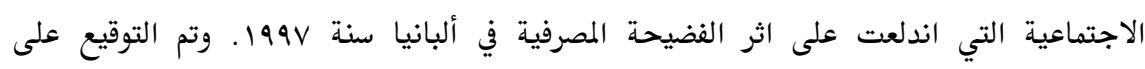

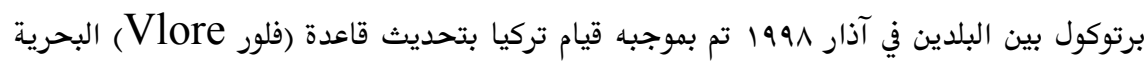

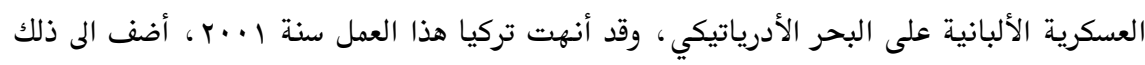

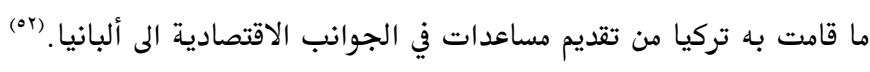
المبحث الثالث: العلاقات التركية- اليونانية بين التنازع والتنافس لعبت الذاكرة التاريخية وتكوين الهوية القومية دورا ههما في تمحور وتوجيه العلاقات التركية-

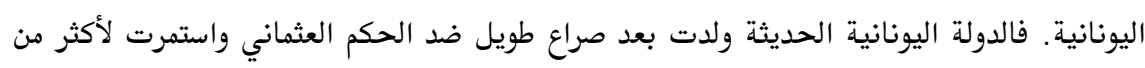
ثمانين سنة وهي توسع أراضيها على حساب الدولة العثمانية، فارتبطت عملية بناء الدولة اليونانية

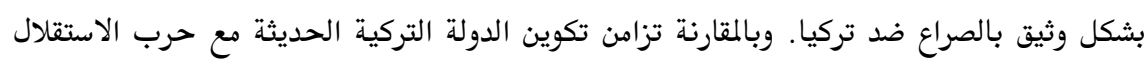

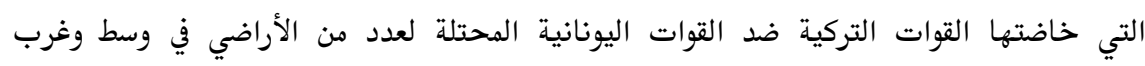

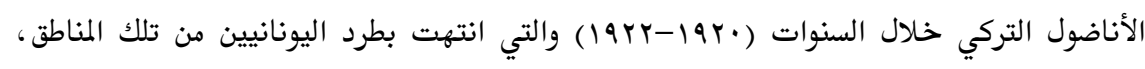

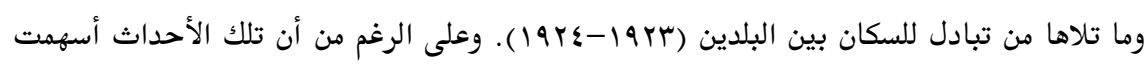
برسم صورة سلبية لكل طرف عن الطرف الأخر وعززت من عدم الثقة المتبادلة بين البلدين فان 
الجانبين وقعا معاهدة صداقة وتعاون سنة بrا9 والتي أنتجت فترة من الوفاق والتعاون استمرت الى

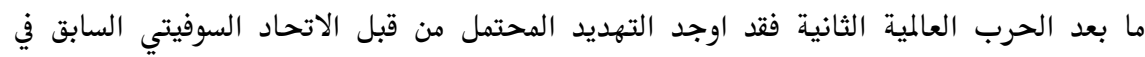

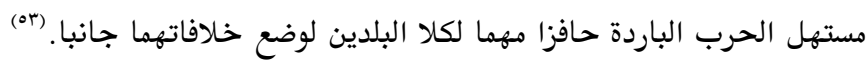

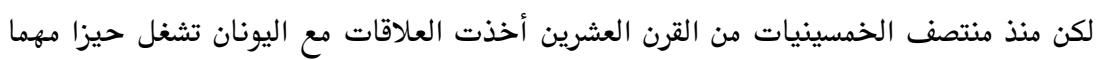

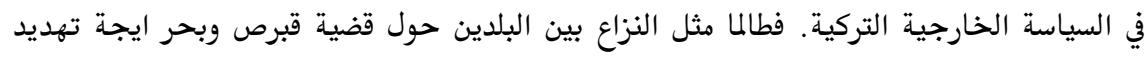

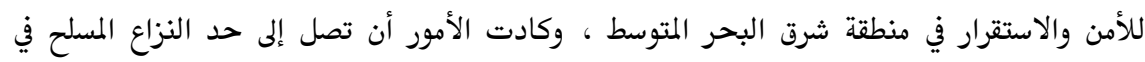

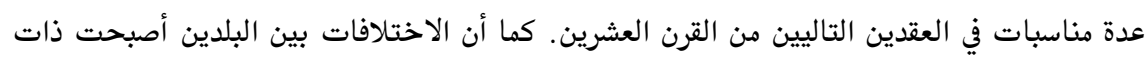

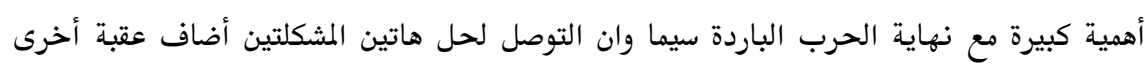

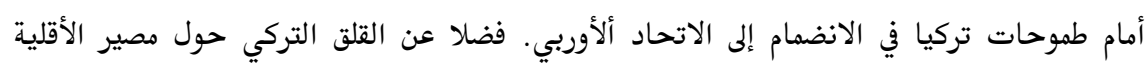
التركية في تراقيا الغربية اليونانية، وظهور البلقان حلبة تنافس بين النفوذ التركي واليوناني.

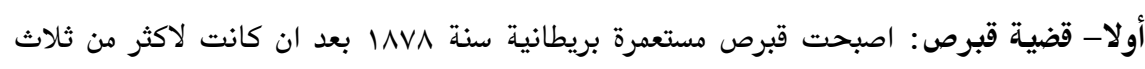
قرون تحت السيطرة العثمانية، وطلما سعى سكانها من القبارصة اليونان الى الاتحاد مع اليونان ضمن حركة اطلق عليها (اينوسيس Enosis)، التي كانت تلقى معارضة من قبل القبارصة الاتراك

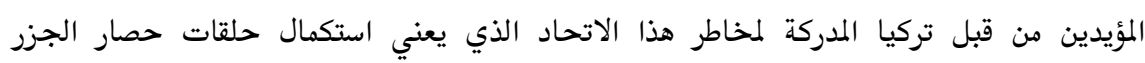

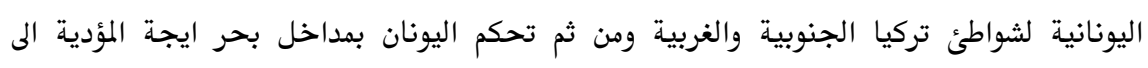
هضيقي الدردنيل والبسفور وجميع الموانئ التركية من اسطنبول غربا حتى الاسكندرونة شرئ تربا.

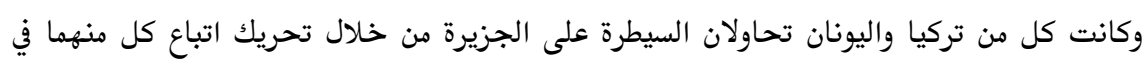

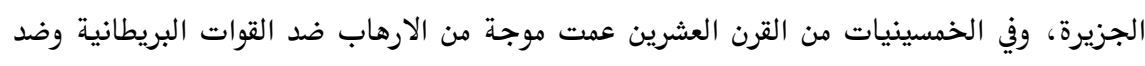

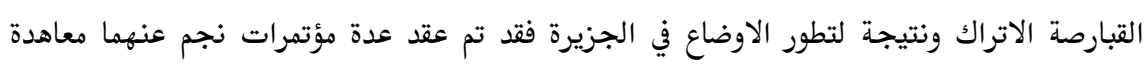

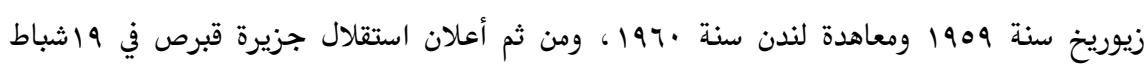

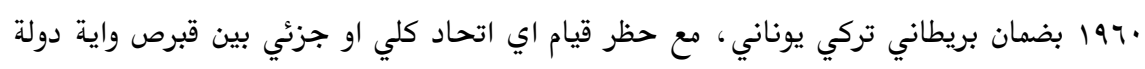

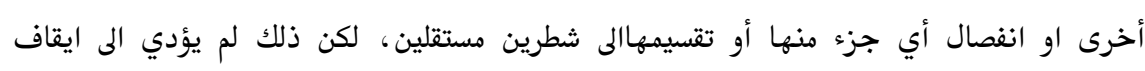

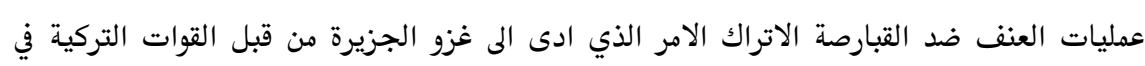




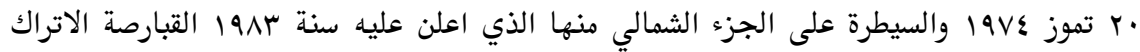

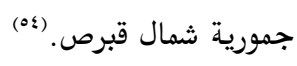

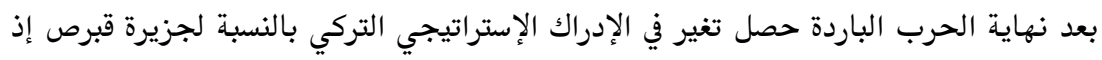

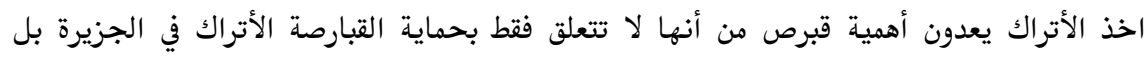
تنبع أهميتها بقدر علاقاتها بأمن تركيا وكونها تمثل حجر زاوية في الدفاع عن الأناضول وتامين حماية نفط بحر قزوين الذي من المتوقع أن ينقل عبر خط أنابيب باكو- جيهان إلى أوربا، وهذا

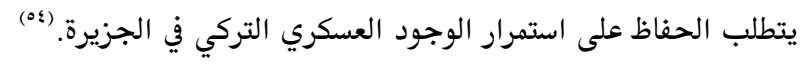

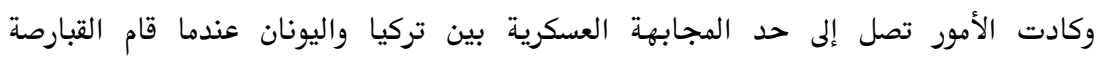

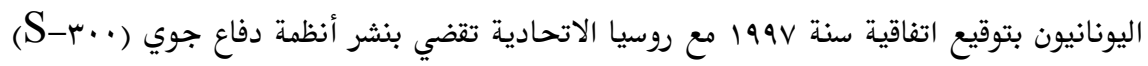

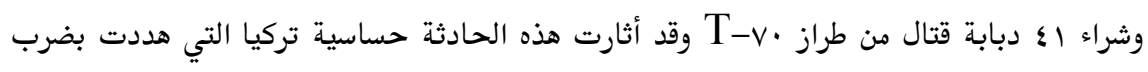

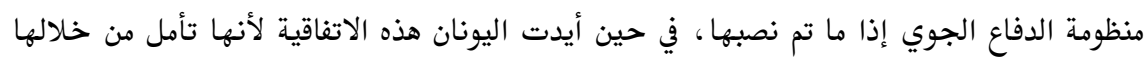

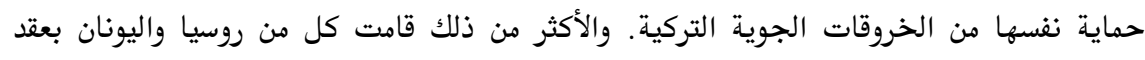

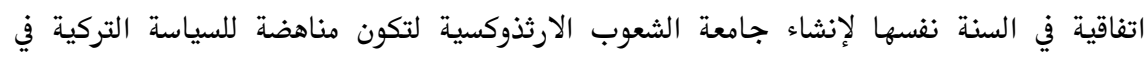

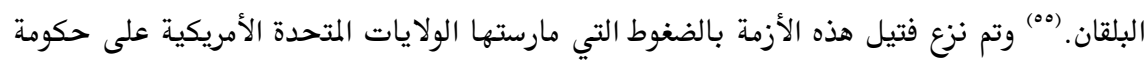

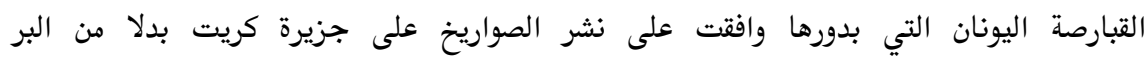

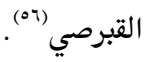

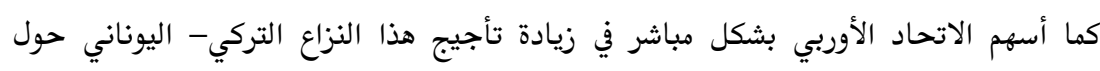
قبرص عندما قرر الاتحاد عام 199V قبول عضوية قبرص اليونانية ورفض قبول تركيا وقبرص التركية، اذ تمثل رد الفعل التركي برفض قبول عضوية قبرص اليونانية لكونها مخالفة لاتفاقية

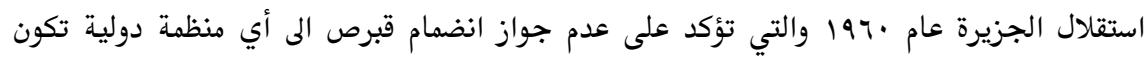

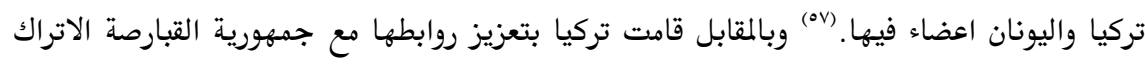
عندما عقدت معها اتفاقا في تموز199V يتم بموجبه تشكيل مجلس مشترك واقامة اتحاد اقتصادي

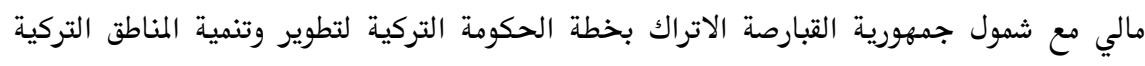


وتحسين روابط النقل بين البلدين، كما بدات تركيا بضم القبارصة الأتراك إلى الوفود التركية الدولية

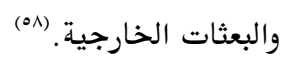

ثانيا- النزاع حول بحر ايجة: النزاع بين تركيا واليونان حول بحر ايجة في حقيقته هو سلسلة من

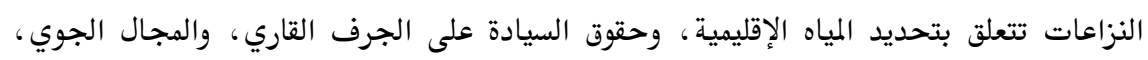

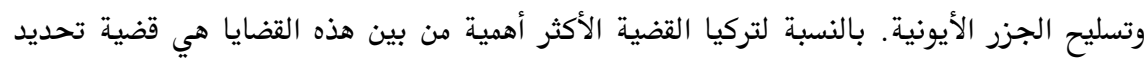

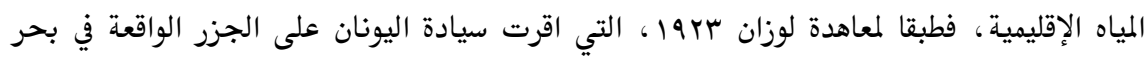

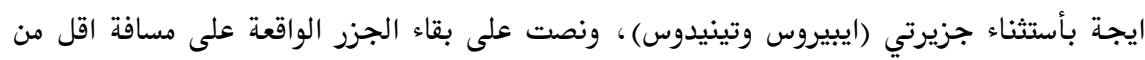
ثلاثة أميال من الساحل الاسيوي تحت السيادة التركية، كانت المياه الإقليمية في بحر ايجة لكل لكل

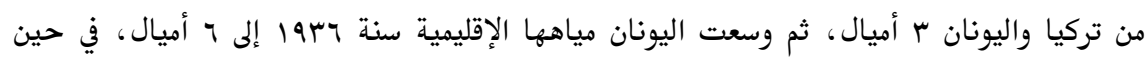

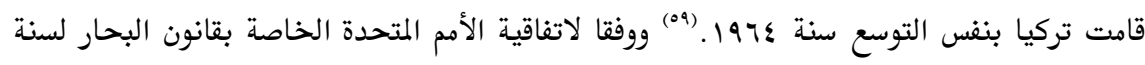
19Ar (اتفاقية لم توقعها تركيا) أعطت اليونان الحق في مد مياهها الإقليمية من ب اميال الى مسافة

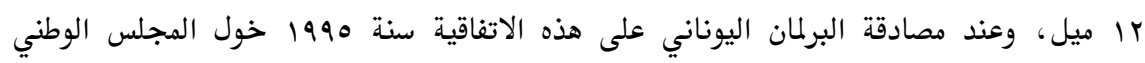

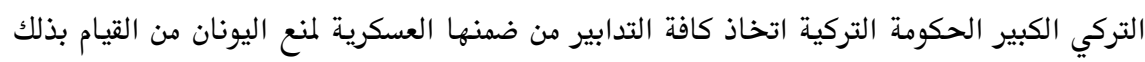

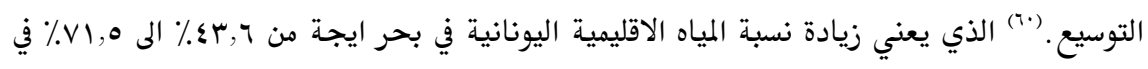

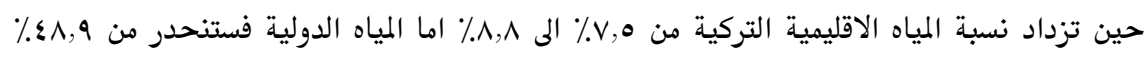

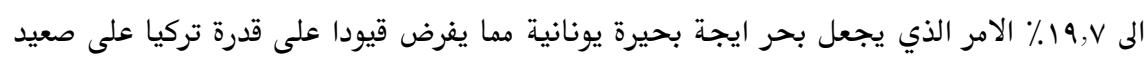
(11). المناورة البحرية التئ) وزاد من حدة التوتر بين تركيا واليونان في بحر ايجة الازمة التي نشبت بين البلدين سنة ب99 199

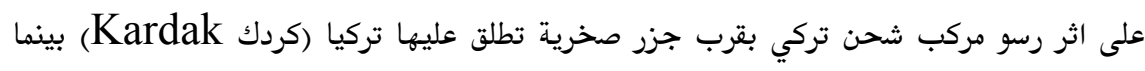

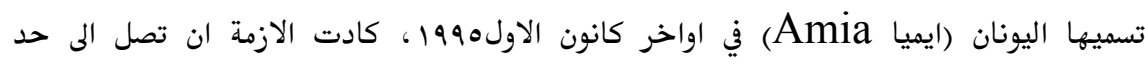

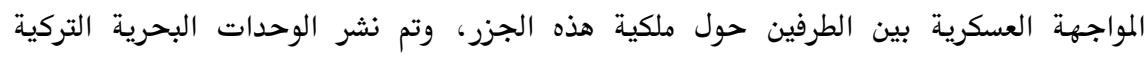

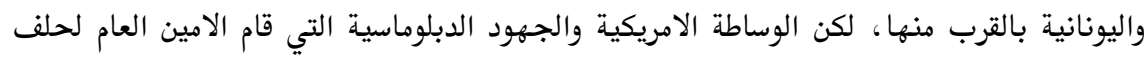

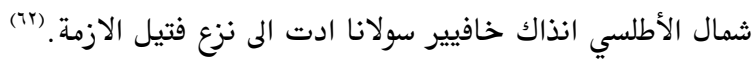


دراسات إقليمية ج (17)

وتختصم تركيا مع اليونان حول المجال الجوي في بحر ايجة أيضا، إذ ترفض تركيا مد المجال

الجوي اليوناني الى لـ أميال وتصر على أن يقتصر حق اليونان على ستة أميال فقط. وتأكيدا على

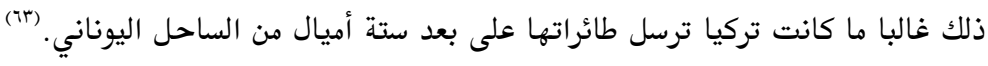

وترى تركيا أمكانية حل هذه القضايا يمكن حلها عن طريق المفاوضات الثنائية بين البلدين بينما

كانت اليونان ترى ان هناك قضية واحدة فقط متنازع عليها مع تركيا في بحر ايجة هي الجرف صدرد

القاري ويمكن حسمها عن طريق محكمة العدل الدولية وهو الأمر الذي ترفضه تركيا. (\$ٔ) اذ ترى اليونان ان خط رسم تحديد الجرف القاري لا يبدأ من سواحل البر الرئيسي لكلا الدولتين ولكن بين لدين

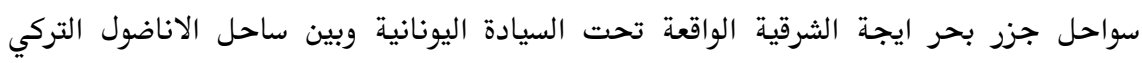

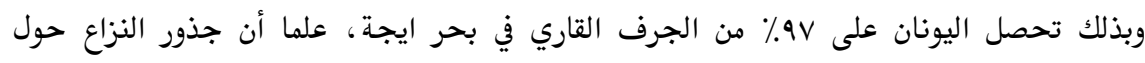

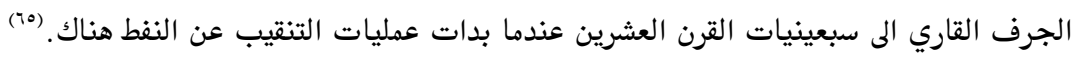

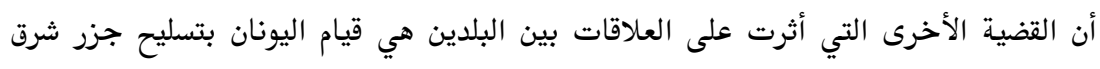

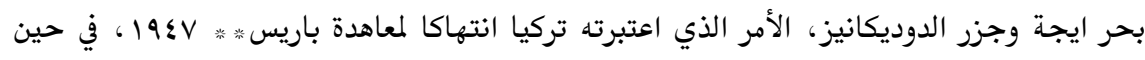
اعتبرته اليونان ردا دفاعيا على ما قامت به تركيا من قوة قوامها مئة الف جندي (الجيش الإيجي

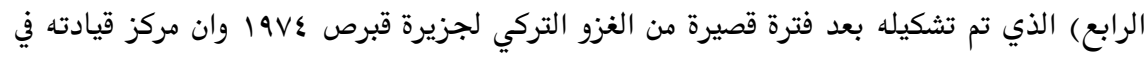

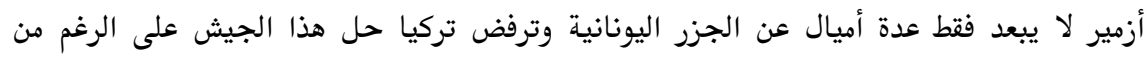

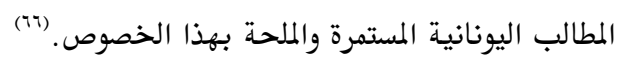
وزاد من وطئة المشاكل التركية مع اليونان على حكومة انقرة انها اصبحت عقبة أخرى أمام

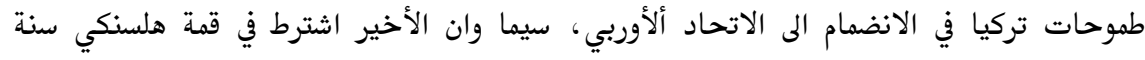

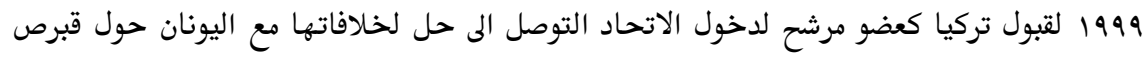
وبحر ايجة، على الرغم من ان اليونان وبضغط امريكي ألغت تحفظها على انضمام تركيا الى الاتحاد ثالثا- الاقلية التركية في اليونان: تعد حالة الاقلية التركية في تراقيا الغربية اليونانية سببا اخرا

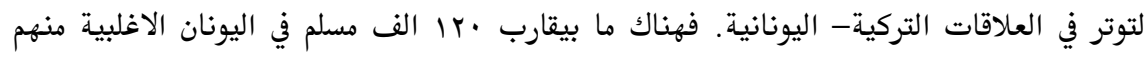

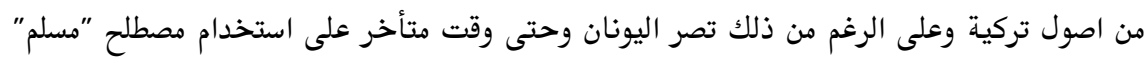


لهذه الاقلية على اساس ان معاهدة لوزان تشير اليهم " مسلمين" وليس اتراك. وتعاني الاقلية

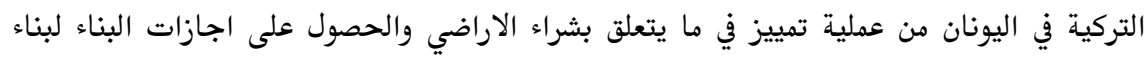

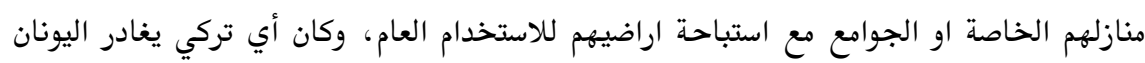

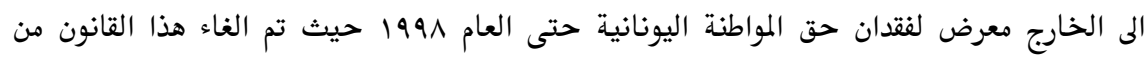

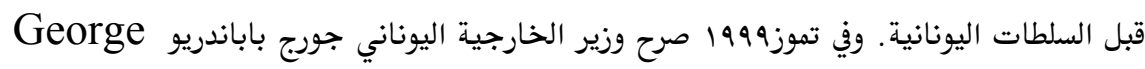
Papandreou

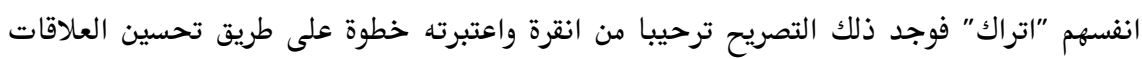
بين البلدين. (1) رابعا- التنافس في البلقان: أضافة لما سبق ذكره فأن تركيا واليونان دخلا في حلبة تنافس حول

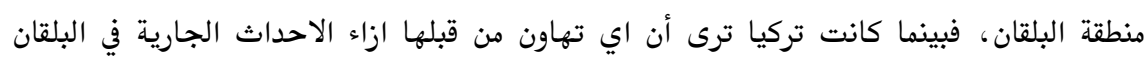

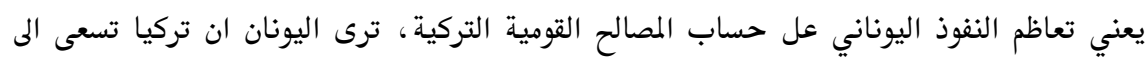

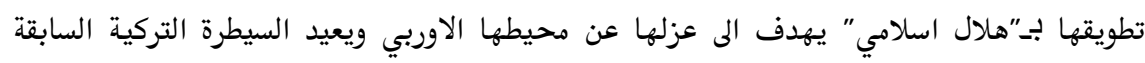
على البلقان. (19) تنبع وجهة النظر اليونانية من ان التحركات التركية في البلقان في فترة ما بعد الحرب الباردة،

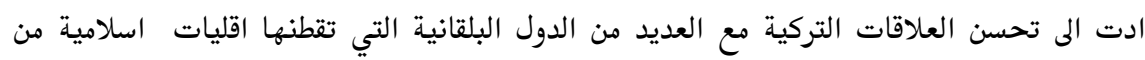

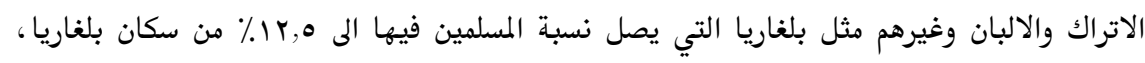

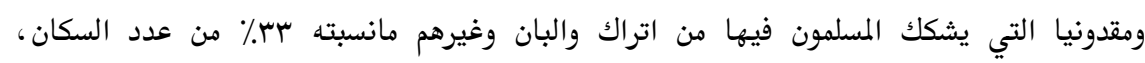

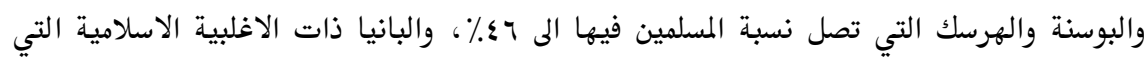

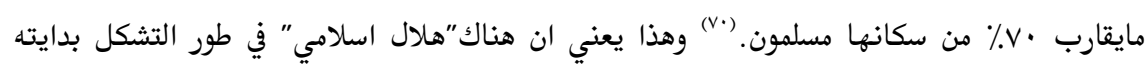
اتراك بلغاريا ونهايته مسلمو البانيا. في الحقيقة لم تحاول تركيا في سياستها البلقانية ان تستخدم الورقة الاسلامية وان كانت مؤثرة،

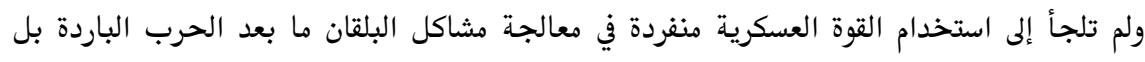

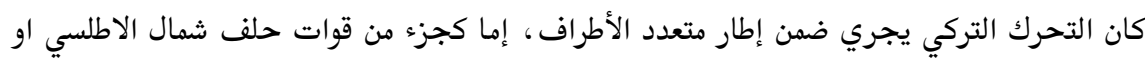
تحت مظلة القوات الدولية بأشراف الأمم المتحدة. (v1) 
كان من نتائج هذه السياسة انتسام دول البلقان الى معسكرين، ضمن جهة تتقاطع مصالح تركيا ومسلمي البوسنة والبانيا ومقدونيا واقليم كوسوفا، مع تحالف اليونان وصربيا، اذ تشكل هطامع

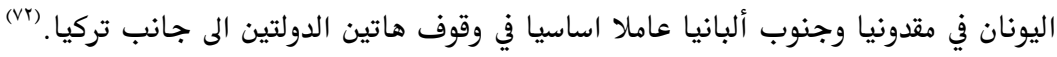
وعلى الرغم من ذلك، اثبتت العلاقات الانسانية انها ممكن ان تتجاوز المشاكل السياسية، فعندما ضربت الزلازل سنة 1999 كل من تركيا واليونان على التوالي قدم كلا الطرفين المساعدات الانسانية للطرف الاخر وشكل ذلك بوادر باتجاه تحسن العلاقات بين البلدين ففي كانون

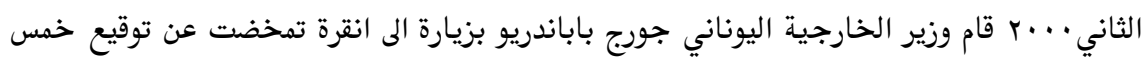

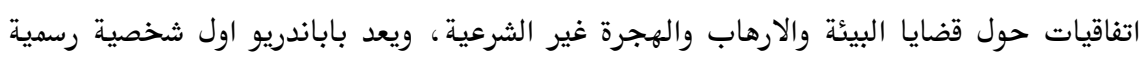

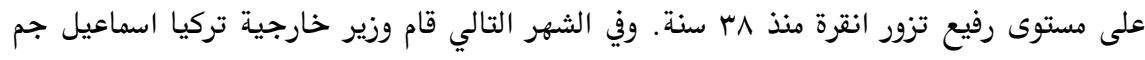

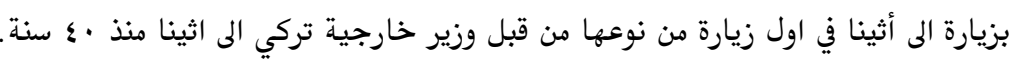

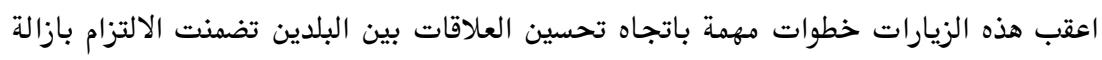
الالغام على طول الحدود اليونانية-التركية والتخطيط لمد طريق سريع يربط منطقة غربي اليونان

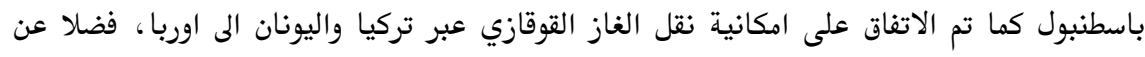
التعاون في التعامل مع الكوارث الطبيعية ، واعادة المهاجرين غير الشرعيين. واتخذت خطوات مهمة في الجانب العسكري ايضا. حيث اعلنت اليونان في نيسان ا.r تغييرات في عقيدتها العسكرية بأنهاء حالة التعبئة الحربية ضد تركيا التي اوجدها الغزو التركي لجزيرة قبرص سنة عVV

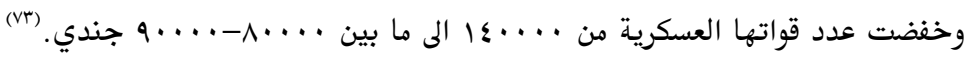


د. عبد شاطر عبد الرحمن
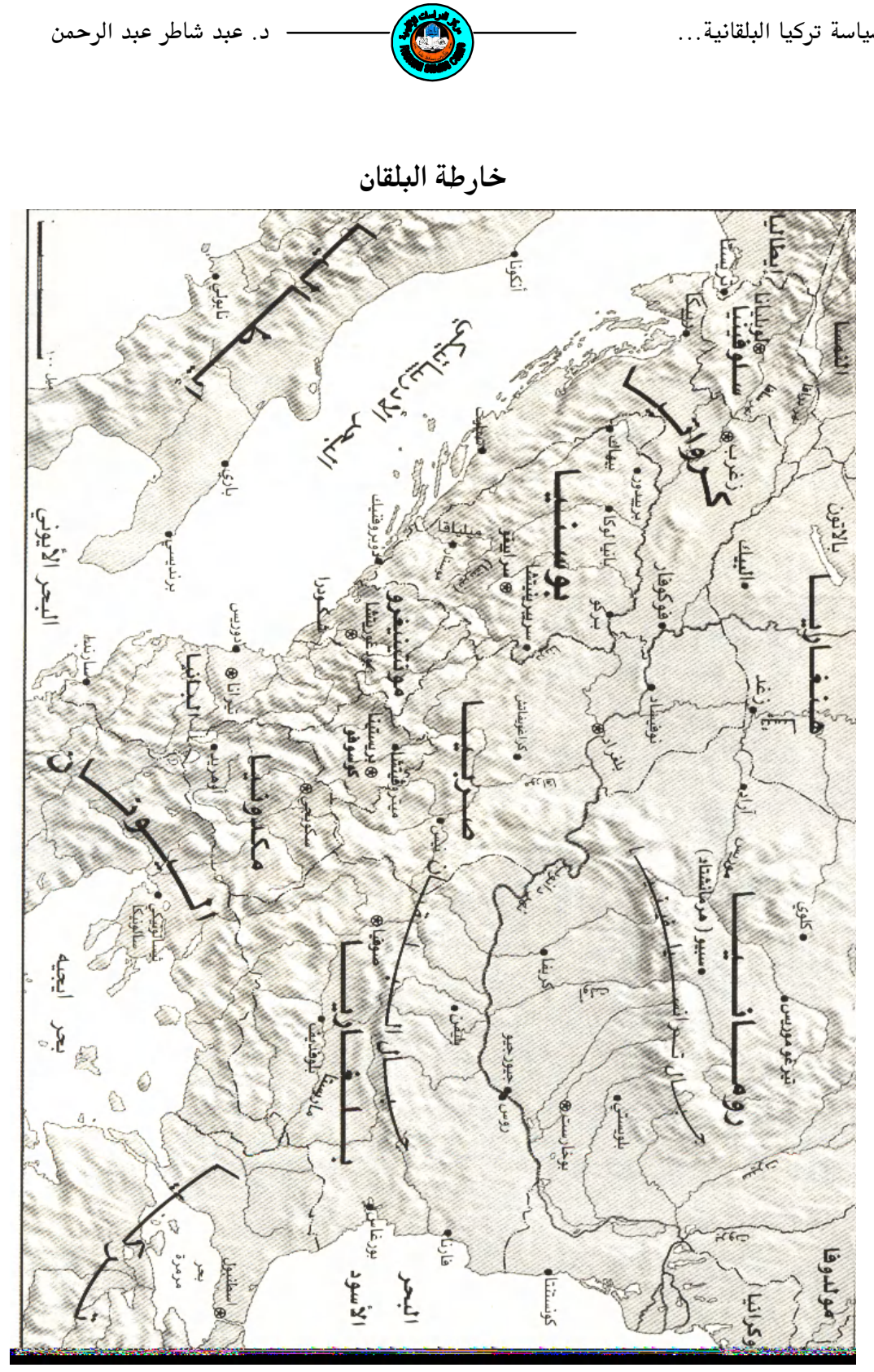

المصدر: اليزابيث بوند، الجولة الأخيرة في البلقان تغير أنظمة الحكم على الطريقة الاوربية، ترجمة ميشيل

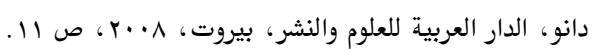


أوجدت العلاقات التاريخية بين تركيا والبلقان التي امتدت لأكثر من خمسة قرون روابط جغرافية وثقافية وتاريخية مع المنطقة البلقانية، وساهمت في خلق وجود أسلامي في العديد من الدول البلقانية، وهناك نظرة إلى المسلمين الذين ينتشرون حاليا في أنحاء عدة من البلقان على إنهم جزء من الإرث العثماني التركي، وإنهم امتداد وذراع لتركيا في المنطقة. وبالمقابل ونتيجة للهجرة المعاكسة من البلقان الى تركيا، يوجد اليوم ما نسبته · ٪٪ من سكان تركيا ذو أصول بلقانية مما يشكل عامل ضغط خارجي وداخلي على الحكومة التركية إزاء رسم سياستها تجاه البلقان. لم تحاول تركيا خلال مساهمتها في معالجة مشاكل البلقان ما بعد الحرب الباردة ان تلعب الورقة الاسلامية على الرغم من أهميتها، خاصة في دعمها لمسلمي البوسنة وكوسوفا، وانما جاء تحركها ضمن إطار متعدد الأطراف، إما كجزء من قوات حلف شمال الأطلسي او تحت مظلة القوات الدولية بأشراف الأمم المتحدة. وقد أسهمت سلسلة المعاهدات الثنائية التي عقدتها تركيا مع عدد من الدول البلقانية الشيوعية السابقة في تعزيز وجودها السياسي والاقتصادي والعسكري في البلقان. ان حرص انقرة على التواجد الفعال والاندماج في مذطقة البلقان ياتي في سياق طموحها للأنظمام الى الاتحاد الاوربي المتاخم للبلقان والمعني بضم جميع الدول البلقانية الى الاتحاد. أما بالنسبة للعلاقات التركية- اليونانية مابعد الحرب الباردة فقد مثلت استمرار لحالة التوتر التي أندلعت بين البلدين منذ منتصف الخمسينيات من القرن العشرين حول قضية قبرص ومن ثم بحر ايجة، وكادت الأمور أن تصل إلى حد النزاع المسلح في عدة مناسبات في التسعينيات من القرن المذكور. واصبحت القضيتين ذات اهمية كبيرة بالنسبة لأنقرة سيما وان التوصل لحل هذين المشكلتين شكل عقبة اخرى أمام طموحات تركيا في الانضمام إلى الاتحاد ألأوربي. وعلى الرغم من ذلك فقد تبادلت كل من تركيا واليونان المساعدات الانسانية عند تعرض بلديهما للزلازل مما اسهم في تحسن العلاقات بين البلدين، وادى الى عقد معاهدات ثنائية حول قضايا البيئة والارهاب والهجرة والاتفاق على تنفيذ بعض المشاريع الاقتصادية المشتركة وانهاء حلة التعبئة العسكرية بين البلدين. 
د. عبد شاطر عبد الرحمن

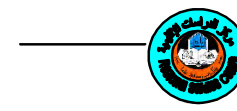

سياسة تركيا البلقانية... 


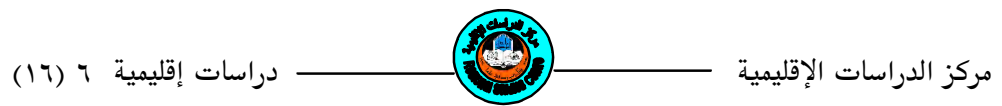

\title{
Turkey's Balkan policy in the post-cold war period (1991-2001)
}

\author{
Fbed Qhater Mrbdul-Rahman

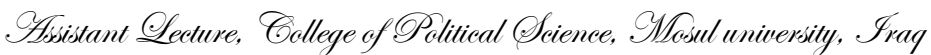

\section{abstract}

Balkan region occupies a significant position in the Turkish strategic perception for the reasons of geographical neighborhood and the national and religious ties. There are Turkish minorities in many Balkan states; moreover, a big percentage of the Turkey people are of Balkan's origins, in addition to the connective relations on the part of the Muslim in the Balkan toward Turkey. The end of the cold war, disassemble of the former Soviet Union, and the collapse of the communist camp erased the barrier in front of the Turkish intervention in the Balkan region. The turkey started an active policy through which it promoted its p0litical, military, and economic relations with many Balkan states.

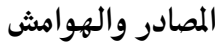

$$
\begin{aligned}
& \text { 1- نزار سمك، البوسنة والصراع الدامي، مركز المحروسة للبحث التدريب النشر، القاهرة، 1999، ص صله }
\end{aligned}
$$


B.J.C. Hurewitz, The Diplomacy in the Near and Middle East. VOL.11, Documentary Record (1914-1945), New York, 1972, pp. 119-127.

4- Zalmay Khalilzad (Others), The Future of Turkish- Western Relation toward a Strategic plan, Rand, Washington, 2004, p. 16.

$$
\begin{aligned}
& \text { 5- نصيف جاسم علي المطلبي، موقع تركيا الجيوستراتيجي واهميته للعراق، دراسة في الجغرافية } \\
& \text { السياسية ، رسالة دكتوراة غير منشورة مقدمة الى مجلس كلية الاداب/ جامعة بغداد، 1919 ا، ص 9؟ } \\
& \text { צ- محمد م الأررناؤط، دراسات في التاريخ الحضاري للاسلام في البلقان، منشورات مؤسسة التميمي للبحث }
\end{aligned}
$$

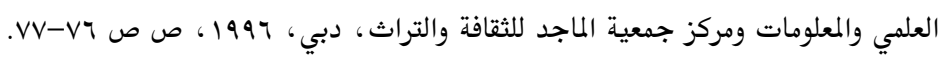

$$
\begin{aligned}
& \text { V- افرإح ناثر جاسم " "توركت أوزال ومشروع العثمانية الجديدة"، مجلة دراسات أقليمية ، تصدر عن مركز }
\end{aligned}
$$

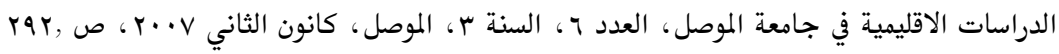

8- Sedat Laciner, "Turkey's EU Membership's Possible Impacts on the Balkans", Turkish Weekly, p.1. Available on: www.turkishweekly.net/Comment.php.id=1777

ه- هاينتس كرامر، تركيا المتغيرة تبحث عن ثوب جديد، التحدي الماثل امام كل من أوربا والولايات

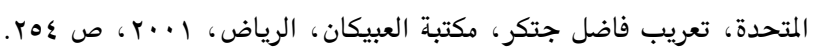
ه1 الارناؤوط، المصدر السابق، ص ص 91,

1ا- بلال شمشير، " اتراك بلغاريا وموضوع الهجرة" في دراسات حول الكيان التركي في بلغاريا، رقم ا،

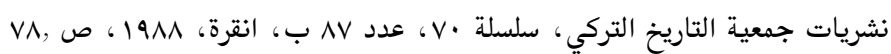

12- C.A Macarthy (edit), Survey of International Affairs 1925, Vol 1-2, Oxford, London, 1928, p. 260.

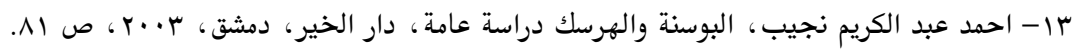

14- Hikmet Öksüz, "Turkey's Balkan Policy (1923-2007)", Turkish Review of Balkan Studies, Foundation for Middle East and Balkan Studies (OBIV), Istanbul, 2007/ 12, p. 146.

15- Ibid, p. 147.

$$
\begin{aligned}
& \text { 17- كرامر، المصدر السابق، ص عهب. } \\
& \text { IV }
\end{aligned}
$$

18- Arnohd Toynbee (edit), Survey of International Affairs 1934, Oxfored, London, 1935. p. 524; Eliza Campus, The Little Entente 
and Balkan Alliance, translated from Romanian by Razdolesch, Bucuresti, 1978, pp. 76-82.

19- وقعت على اتفاق مونترو جميع الدول التي شاركت في مؤتمر لوزان بأستثناء ايطاليا، لمزيد من

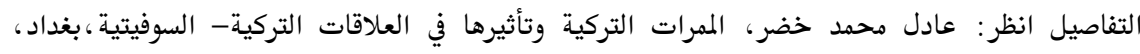

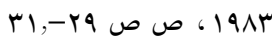

20- Öksüz, Op.Cit, p. 136.

21- Ibid, p. 141.

$$
\begin{aligned}
& \text { r r- نزار اسماعيل عبد اللطيف، "التنافس الروسي- التركي على اقليم البلقان بعد الحرب الباردة"، مجلة }
\end{aligned}
$$

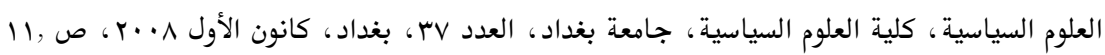

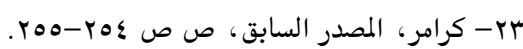

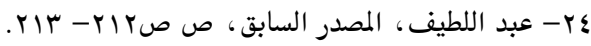

$$
\begin{aligned}
& \text { هץ- خليل ابراهيم السامرائي، "الانعكاسات الاقليمية للحرب في البلقان"، مجلة دراسات سياسية، يصدرها }
\end{aligned}
$$

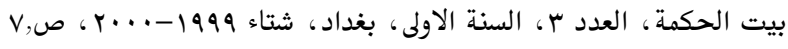

$$
\begin{aligned}
& \text { r ror, كرامر، المصدر السابق، ص } \\
& \text { V r - عبد شاطر عبد الرحمن، " تفكك يوغسلافيا وانهيار مشروع صربيا الكبرى"، مجلة دراسات اقليمية، }
\end{aligned}
$$

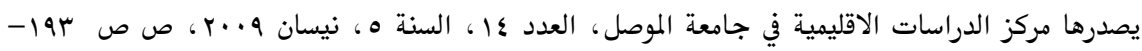

$$
\begin{aligned}
& r \cdot r, \\
& r \cdot \Lambda, ~ ص \wedge
\end{aligned}
$$

29- Vesna Pesic; Serbian Nationalism and the Origins of the Yugoslav Crisis, United State Institute of peace, Washington, 1996, pp. 21-22.

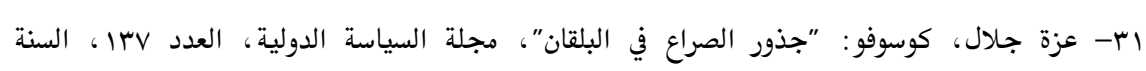

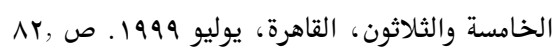

بr

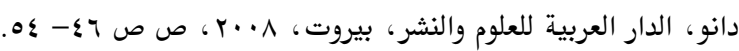

33- Stephen Larrbee, and Ian O. Lesser, Turkish Foreign Policy in Age of Uncertainty, Rand, Washington, 2003, p. 94.

34- Öksüz, Op.Cit, p. 152. 


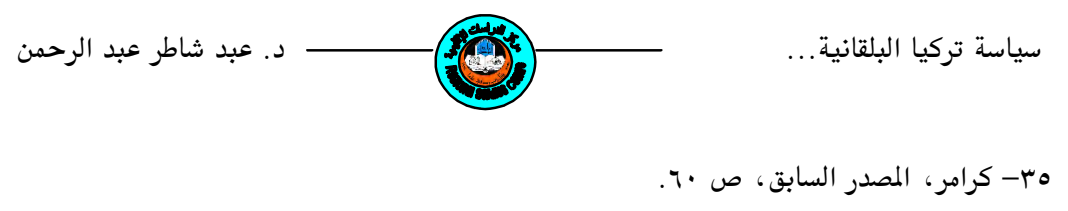

36- Mesut Özen," An Overview Turkey's Policy in the Balkan and Middle East In the 1990's", Turkish Review of Balkan Studies, Foundation for Middle East and Balkan Studies (OBIV), Istanbul, 2003/ 8, pp. 34-35.

37- Öksüz, Op.Cit, p. 173.

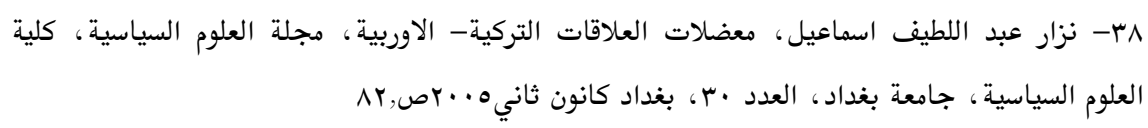

39- Öksüz, Op.Cit, pp. 175-176.

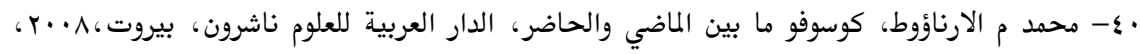
ז

41- David Anderson, The Collapse of Yugoslavia: Background and Summary, the parliamentary library, Australia, 1995, p.6.

42- Pesic, Op.Cit, p. 15.

$$
\text { بـ- بوند، المصدر السابق، ص ص ז؟1--10. }
$$

44- Öksüz, Op.Cit, p. 152.

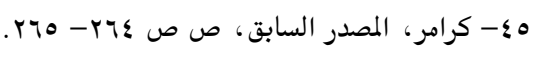

46- Khalilzad, Op.Cit, p. 17.

47- Özen, Op.Cit, pp. 36-37.

48- Öksüz, Op.Cit, pp. 176-177.

49- Özen, Op.Cit, p. 36.

50- Larrbee, and Lesser, Op.Cit, p. 95.

51- Özen, Op.Cit, p. 36.

52- Öksüz, Op.Cit, pp. 170-171.

53- Larrbee, and Lesser, Op.Cit, pp. 72-73.

§ه- عصدت برهان الدين عبد القادر، "العلاقات التركية- اليونانية |A9V-|Ar|" مجلة اوراق تركية

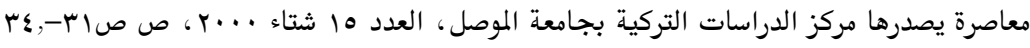

55- Larrbee, and Lesser, Op.Cit, p. 79.

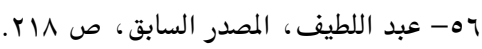

57-Larrbee, and Lesser, Op.Cit, p. 79.

PAه- عبد اللطيف، المصدر السابق، ص rIV

59- Larrbee, and Lesser, Op.Cit, p. 80. 


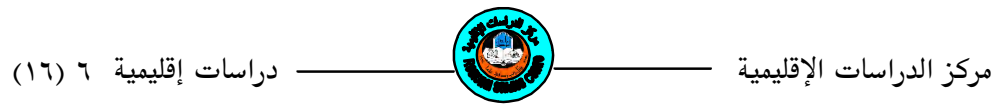

60- Nilüfer Oral," Certain Legal Aspects of the Agean Sea", Turkish Review of Balkan Studies, Foundation for Middle East and Balkan Studies (OBIV), Istanbul, 2000/01. 5, pp. 70-71.

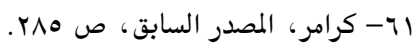

62- Oral, Op.Cit, p. 71.

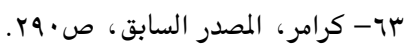

64- Larrbee, and Lesser, Op.Cit, p. 75.

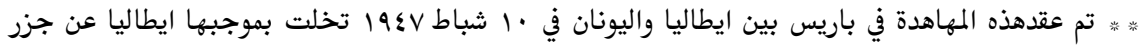

الدوديكانيز الاثني عشر التي كانت قد احتلتها من الدولة العثمانية سنة 1911 لصالح اليونان وبموافقة

تركيا شرط ان تكون مذزوعة السلاح بشكل كامل، انظر:

Fuat Aksu, "Preservation Demilitarized Status of the Aegean Islands for the National Security of Turkey" Turkish Review of Balkan Studies, Foundation for Middle East and Balkan Studies (OBIV), Istanbul, 2002/03. 5, pp. 118-124.

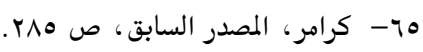

66- Oral, Op.Cit, p. 74.

67- Larrbee, and Lesser, Op.Cit, p. 75.

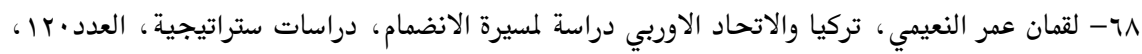

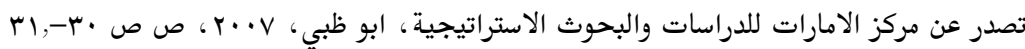

69- Larrbee, and Lesser, Op.Cit, p. 85.

70- Xavier Bougarel, The Role of Balkan Muslims in Building a European Islam, European Policy Centre, EPC Issue paper NO. 43, 23 November 2005, p. 8. Available on: www.epc.eu/twen/pdf.

71- Sylvie Gangloff," The Weight of Islam in the Turkish Foreign Policy in the Balkan", Foundation for Middle East and Balkan Studies (OBIV), Istanbul, 2000/01. 5, pp. 92- 94.

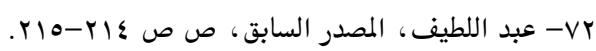

73- Larrbee, and Lesser, Op.Cit, pp. 84-85. 